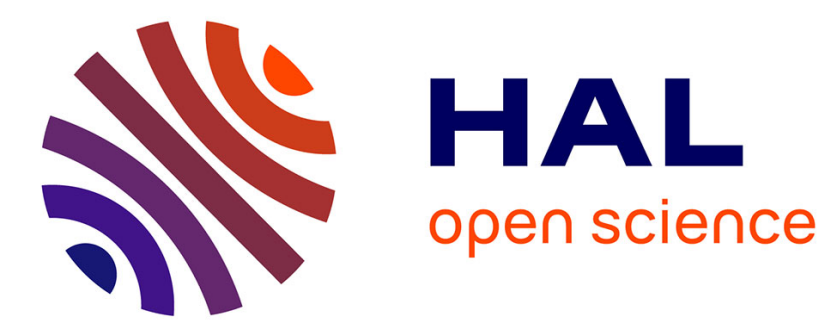

\title{
Ultraslow, slow, or fast spreading ridges: Arm wrestling between mantle convection and far-field tectonics
}

\author{
Laurent Husson, Philippe Yamato, Antoine Bezos
}

\section{To cite this version:}

Laurent Husson, Philippe Yamato, Antoine Bezos. Ultraslow, slow, or fast spreading ridges: Arm wrestling between mantle convection and far-field tectonics. Earth and Planetary Science Letters, 2015, 429, pp.205-215. 10.1016/j.epsl.2015.07.052 . insu-01191512

\section{HAL Id: insu-01191512 \\ https://hal-insu.archives-ouvertes.fr/insu-01191512}

Submitted on 2 Sep 2015

HAL is a multi-disciplinary open access archive for the deposit and dissemination of scientific research documents, whether they are published or not. The documents may come from teaching and research institutions in France or abroad, or from public or private research centers.
L'archive ouverte pluridisciplinaire HAL, est destinée au dépôt et à la diffusion de documents scientifiques de niveau recherche, publiés ou non, émanant des établissements d'enseignement et de recherche français ou étrangers, des laboratoires publics ou privés. 


\title{
Ultraslow, slow, or fast spreading ridges: arm wrestling between mantle convection and far-field tectonics
}

\author{
Laurent Husson $^{\mathrm{a}, *}$, Philippe Yamato ${ }^{\mathrm{b}, \mathrm{c}}$, Antoine Bézos $^{\mathrm{d}}$ \\ a ISTerre, CNRS UMR 5275, Université de Grenoble, France \\ ${ }^{b}$ Géosciences Rennes, CNRS UMR 6118, Université de Rennes-1, France \\ ${ }^{c} G F D$, Department of Earth Sciences, ETH-Zurich, Switzerland \\ ${ }^{d} L P G$ Nantes, CNRS UMR 6112, Université de Nantes, France
}

\section{Abstract}

Oceanic spreading rates are highly variable, and these variations are known to correlate to a variety of surface observables, like magmatic production, heat flow or bathymetry. This correlation lead to classify ridges into fast and slow spreading ridges, but also into the more peculiar ultraslow spreading regime. Here we explore the dynamic relationships between spreading ridges, plate tectonics and mantle flow. We first focus on the thermal signature of the mantle, that we infer from the global S-wave seismic tomography model of Debayle and Ricard (2012). We show that the thermal structure of ridges gradually departs from the half-space cooling model for slow, and above all ultraslow spreading ridges. We also infer that the sublithospheric mantle temperature decreases by more than $150^{\circ} \mathrm{C}$ from fast to ultraslow spreading regimes. Both observations overall indicate that the mantle convection pattern is increasingly chaotic underneath slow and ultraslow spreading ridges. We suggest that this is due to far-field tectonics at the other ends of lithospheric plates: not only it modulates the spreading rates but it also alters the convection regime by obstructing the circulation of plates, which in turn modifies the surface kinematic conditions for the convecting mantle. We test this hypothesis using a thermo-mechanical model that represents a convection cell carrying a continental lithosphere atop. The continent gradually drifts away from the spreading ridge, from which the oceanic lithosphere grows and cools while the continent eventually collides at the opposite side. In turn, this event drastically modifies the upper kinematic condition for the convecting mantle that evolves from a mobile lid regime to an almost stagnant lid regime. Implications on spreading ridges are prominent: heat advection decreases with respect to thermal conduction, which causes the oceanic lithosphere to thicken faster; the oceanic plates get compressed and destabilized by a growing number of small scale transient plumes, which disrupt the structure of the oceanic lithospheres, lower the heat flow and may even starve ultraslow ridges from partial melting. It follows that the spreading rate of a modern ridge mirrors its status in the global plate tectonics framework within a unique breakup, drift, collision scenario, within the transition from mobile to stagnant lid, and that it is the same mechanism that build mountains at converging boundaries and control spreading rates. Oceanic ridges thus can be regarded as a sensor of the resisting rather than driving forces. Both the model and the seismic structure of the mantle underneath 
ridges reveal that the temperature variations are largest at shallow depths in the upper mantle, i.e. at the critical depth where the melt supply to the above ridges can be modulated, thereby also explaining why slow and ultraslow ridges are almost exclusively associated to cold mantle. It follows that the chemistry of oceanic ridge basalts may not strictly reveal the mantle potential temperature, but the variations in the sublithospheric temperature field.

Key words: ultraslow spreading ridges, mantle convection, plate tectonics, seismic tomography, magmatism

\section{Introduction}

Mid-oceanic ridges display a wide range of tectonic velocities. Similarly to subduction rates, spreading rates have been tentatively correlated to a variety of physical, geochemical, and morphological characteristics of spreading ridges (e.g. Chen and Morgan, 1990; Bown and White, 1994; Shen and Forsyth, 1995; Klein and Langmuir, 1987). The most striking results is the remarkably uniform crustal thickness for ridges with spreading rate above $15 \mathrm{~mm} / \mathrm{yr}$ ( $\sim 7 \mathrm{~km}$; Chen, 1992; White et al., 1992), excepted near hotspots and fracture zones. However, this monotonic rule breaks down for very low spreading rates (i.e. at ultraslow spreading ridges, below the threshold value of $15 \mathrm{~mm} / \mathrm{yr}$ ), where thinner crusts are systematically observed (Reid and Jackson, 1981). The observation that the ultraslow South West Indian Ridge (SWIR) and Gakkel ridges (fig. 1) are $a$-volcanic, and possibly $a$-magmatic (Cannat, 1993; Dick et al., 2003; Cannat et al., 2008), eventually attests for a low melt supply that do not fulfills the demand for a $\sim 7 \mathrm{~km}$ thick crustal layer. This property has been interpreted as resulting from a variety of processes, including mantle composition (Zhou and Dick, 2013), melt focussing within the mantle (Dick et al., 2003; Chen, 1992), along axis melt redistribution (Fox et al., 1995; Curewitz and Karson, 1998; Chen, 1992; Sauter et al., 2011), shortening of the melting column within a thicker conductive thermal lid (Reid and Jackson, 1981), ridge obliquity relative to plate motion (Dick et al., 2003), or simply by overall lower mantle temperature (Cannat, 1993). Hydrothermal cooling within the variable fracture networks at slow and fast ridges is also often invoked (Phipps Morgan and Chen, 1993). However, the cause of this lower thermal regime remains unclear at the ridge scale, for departure from a mean spreading rate is also interpreted as depending on the deep thermal regime, implying that buoyancy driven mantle flow controls the behavior of ridges (e.g. Sotin and Parmentier, 1989; Su et al., 1994). Ultraslow ridges would correspond to a cool enough mantle to starve ridges from the magmatic supply.

* Corresponding author

Email addresses: laurent.husson@ujf-grenoble.fr (Laurent Husson) 
Here, we explore the possibility that plate tectonics and continental drift not only modify plate velocities -including spreading rates- but may also alter the pattern of the long-wavelength thermal regime of the mantle, in particular at shallow depths where it may disturb oceanic accretion. We suggest that spreading rates are not modulated by the vigor of the underlying mantle convection but instead by the tectonics acting at the opposite plate boundaries. This reasoning is driven by kinematic clues: spreading of the $S W I R$ was twice faster before the Late Eocene onset of the Alpine collision between the African and Eurasian plates, and gradually decreased from that time onwards (see for instance the reconstructions of Müller et al., 2008), reflecting the declining northward absolute velocity of the African plate (e.g. Dewey et al., 1989; Silver et al., 1998). To the North, the Alpine collision increased the resistance to plate motion and impedes further northward motion of Africa; to the South, the Antarctic plate, being circumscribed by ridges, also opposes any motion. Overall, we hypothesize that this change in the dynamics of the Tethyan margin modulated the spreading rates of the $S W I R$ down to its current value. The second modern example, viz. the Gakkel ridge, always spread at low rates, due to the resistance at the opposed plate boundaries of the massive Eurasian and North American continents that systematically precluded fast spreading. Overall, we suggest that the effect of continental aggregation or slab anchoring at active margins is to prevent plate motion and alter mantle flow by changing the surface boundary condition from mobile lid to sluggish or stagnant lid (Yamato et al., 2013). This mechanism would in turn decrease the heat supply to the mantle underneath ridges in particular, thereby modulating primordial features such as magmatic productivity and crustal thickness, heat flow, ridge bathymetry, and lithospheric ageing. In the following, we investigate the intricate relationships between plate tectonics, mantle convection and ridge spreading, first by means of an analysis of the seismic geometry of the spreading lithospheres near their ridges, and secondly thanks to a thermomechanical model designed to test our hypothesis on the dynamics of the system and to predict the thermal evolution of the spreading lithosphere.

\section{Seismic structure of spreading lithospheres and mantle temperature variations}

The common understanding that the thermal structure of the lithosphere obeys a first-order dependence on the square root of age has been inferred for long (e.g. Parsons and Sclater, 1977; Turcotte and Schubert, 2002). Seismic tomography independently validated this theory wherein oceanic plates are thermal boundary layers cooling over the convecting mantle (Ritzwoller et al., 2004; Debayle and Ricard, 2012). But a closer examination of the tomography model of Debayle and Ricard (2012) yields more: the age dependence of the thermal structure of the lithosphere, which is satisfactorily evidenced when all plates are merged (fig. 2a), improves when excluding slow moving lithospheres $(<40 \mathrm{~mm} / \mathrm{yr}$, fig. $2 \mathrm{~b})$ and conversely degrades for slow plates only (fig. 2c). Slow moving lithospheres are less well structured than faster ones. This threshold is not random, as the analysis of Debayle and Ricard (2013) of the seismic anisotropy underneath the oceanic 
Another consideration arises from the fact that the oceanic lithospheres are thicker for slow spreading ridges (fig. 3). This implies that the parametrization for the half-space cooling theory needs to be adjusted depending on the spreading rate. When possible, we thus tentatively extract the thickness $z$ of the thermal lithosphere from seismic tomography by assigning a specific wave speed anomaly to the bottom of the lithosphere (fig. 4a, for $\Delta V_{s}=0 \%$ and $\Delta V_{s}=-1 \%$ ) at a common and supposedly mature age of 65-70 Ma (to avoid local artifacts nearby ridges). The thickness of the seismic lithosphere clearly decreases with increasing spreading rates. One can further use this relationship as an indirect probe of the temperature variations in the sub-lithospheric mantle, on the basis of the half-space cooling theory, which relates the mantle temperature $T_{m}$ to plate age $t$, such that

$$
T_{m}=\frac{T_{L}-T_{0}}{\operatorname{erf}\left(\frac{z}{2 \sqrt{\kappa t}}\right)}+T_{0},
$$

lithospheres shows that only the motion of plates moving faster than $40 \mathrm{~mm} / \mathrm{yr}$ correlates to mantle flow, while the direction of motion of slow (and ultraslow) plates does not. Although the observation could be biased because of the fact that the small motion of slow plates is more erratically assessed and can quickly mantle flow statistically holds, regardless of the reference frame.

This observation is even more striking when considering the spreading lithospheres in isolation, carefully selecting areas where ridges are spreading the most regularly (blue outlines in fig. 1). The seismic structure of the lithospheres degrades from fast, to slow, and ultraslow ridges (fig. 3): The fastest spreading East Pacific Rise and Pacific-Antarctic ridge display an unambiguous signature. To a lesser extent, the South-East Indian Ridge and the slow spreading lithospheres (South Atlantic, Central Indian, South Atlantic, Carls, Central Atlantic and North Atlantic) still resemble a half-space cooling. Last, the ultraslow spreading of Debayle and Ricard, we interpret this degradation in the seismic signature as the fact that below a certain rate of spreading or absolute motion, plate tectonics are at odds with the underlying mantle circulation. At least, we interpret this observation as a symptom of a disturbed convective system for the mantle under slow spreading ridges.

where $T_{0}$ is the surface temperature, $T_{L}$ and $z$ are the temperature and thickness of the thermal boundary layer, and $\kappa$ is the thermal diffusivity (e.g. Turcotte and Schubert, 2002). Setting $T_{0}=0^{\circ} C, T_{L}=1100^{\circ} C$ and $\kappa=1 \mathrm{~mm} \mathrm{~s}^{-2}$ allows solving for $T_{m}$ underneath each spreading ridge. Sublithospheric temperatures quickly drop -monotonously yet not linearly- with decreasing spreading rates.

Interpreting this temperature drop in terms of mantle temperature (reference value $T_{m}{ }^{\star}$, that would be the temperature underneath the EPR and Pacific-Antarctic) suggests that the mantle is $\sim 100^{\circ} \mathrm{C}$ colder 
beneath the $S E I R, \sim 100^{\circ} \mathrm{C}$ beneath the $C I R$ and South Atlantic ridges, $\sim 140^{\circ} \mathrm{C}$ beneath the Carlsberg ridge, and possibly $180^{\circ} \mathrm{C}$ beneath the North Atlantic. The mantle under the Central Atlantic ridge is also much colder than the fast-spreading ridges, but nevertheless slightly departs from the tendency. Of course, this exercise has some limitations: first, it is only valid under the half-space cooling approximation, which -based on the above observations- is increasingly erroneous with decreasing spreading rates; second, ultraslow ridges are so unstructured (fig. 3) that any attempt to infer their lithospheric thicknesses -and therefore the mantle temperatures that would derive from these estimates- is meaningless. Regardless, it follows from the apparent relationship between spreading rates and sublithospheric mantle temperatures that the mantle should be even colder underneath ultraslow spreading ridges. The slower oceanic plates spread apart, the colder the underlying mantle temperature; by extrapolating the inferred relationship, we thus anticipate that the mantle temperature underneath ultraslow spreading ridges is colder by $\sim 180^{\circ} \mathrm{C}$ or more than the mantle temperature underneath fast spreading ridges, but only $\sim 50^{\circ} \mathrm{C}$ than the mantle temperature underneath slow spreading ridges.

Not surprisingly, the seismic signature of the mantle underneath the ridge also reveals the same tendency. Although it would be particularly rash to directly convert wave speed anomalies into temperature anomalies underneath ridges, we note that spreading rates globally correlate with wave speed anomalies at sub-lithospheric depths, the faster the spreading the slower the shear wave velocity (figs. 3 and $4 \mathrm{~b}$ ). This result is in accord with Humler et al. (1993) who found a correlation between basalt chemistry and long wavelength pattern of seismic tomography underneath ridges. The more recent and therefore better documented- tomography model that we use here confirms this trend at shorter wavelengths. Interestingly, this correlation vanishes at depths and eventually becomes insignificant at depths greater than $\sim 200 \mathrm{~km}$, suggesting that the thermal field is chiefly disturbed in the uppermost mantle. The sublithospheric mantle temperature results from the competition between heat advection from below and heat conduction towards the surface. Thus, our observation either suggests that conduction is higher or that advection is lower. The following thermo-mechanical model allows to discriminate and rule out conduction as the sole possible cause.

Our investigation of the seismic tomography underneath the oceanic lithosphere outlines the links between spreading rates and mantle temperature. We also find that these relationships only hold down to a critical value for spreading rates. Below this value $(15 \mathrm{~mm} / \mathrm{yr}$, at the transition between the slow and ultraslow spreading regimes) the half-space cooling model breaks down, suggesting that the mantle convects regardless of the overriding spreading ridges, or at least in a partially incoherent manner. These findings by themselves do not permit to discriminate an interpretation where a cool, feeble mantle flow is only able to excite ridges at slow rates, from the alternative process that we explore below where it is plate tectonics that modulates the upper kinematic condition for an equally vigorous mantle flow, and eventually alter the 
general convective regime when spreading rates become too slow.

\section{Thermo-mechanical modeling of spreading ridges}

\subsection{A simplified model for the South West Indian Ridge, Tethyan subduction, and Alpine collision}

Our dynamic model is designed to capture the essential features of the $S W I R$, which is the most documented of the poorly represented class of ultraslow ridges. Its spreading is likely controlled by a mantle conveyor belt that drives the African plate from the $S W I R$, away from Antarctica and towards Eurasia. More specifically, the African plate converges towards Eurasia, being pulled by the Tethyan subduction to the North and pushed from the South (ridge push) and from below (mantle drag) by the upwelling mantle arising from the African superplume (Lithgow-Bertelloni and Silver, 1998; Forte et al., 2010). A convection cell, excited by the upwelling mantle to the South and the downwelling mantle to the North, propels the African plate. But spreading rates decreased in the aftermath of the closure of the Tethys by more than $50 \%$ (e.g. Müller et al., 2008). This temporal scenario therefore encompasses a variety of spreading settings, from a slow spreading regime to an ultraslow spreading regime, that correspond to the pre- and post-collisional times, respectively. Below we model the chain of consequences of the continental collision of the African and Eurasian plates that opposes further divergence between the African and Antarctic plates, which in turn altered the underlying mantle flow but not its power. This simplified model is designed to capture the essential features of this scenario and predict the incidence of surface plate tectonics on mantle flow, spreading rates, ridge geometry, mantle temperature and heat flow, that one can compare to independent observables.

\subsection{Numerical model}

The numerical code used in this study is in two dimensions (2-D) and thermo-mechanically coupled. For details regarding its mechanical part, we refer to Yamato et al. (2012). It solves the Stokes equations (equations (2) and (3)) under the incompressibility constraint (4):

$$
\begin{gathered}
-\frac{\partial P}{\partial x}+\frac{\partial \sigma_{x x}}{\partial x}+\frac{\partial \sigma_{x z}}{\partial z}=0, \\
-\frac{\partial P}{\partial z}+\frac{\partial \sigma_{z z}}{\partial z}+\frac{\partial \sigma_{z x}}{\partial x}=\rho g, \\
\frac{\partial V x}{\partial x}+\frac{\partial V z}{\partial z}=0,
\end{gathered}
$$

where $P, \sigma_{i j}, \rho$ and $g$ are the pressure, deviatoric stress tensor, density and gravitational acceleration, respectively. $V x$ and $V z$ are the two components of the velocity vector in the 2-D $(x, z)$ Cartesian coordinate system. These equations are discretised on a Eulerian-staggered grid over the model domain using a finite 
difference method (Gerya and Yuen, 2003, 2007). Material properties (viscosity and density) are carried by Lagrangian markers. At each time step, these properties are interpolated from the markers to the finite difference mesh using distance-dependent interpolation to solve the Stokes problem. All markers then move according to the obtained velocity field. This numerical scheme was already intensively tested (e.g. Yamato et al., 2012) and already applied with linear viscous materials at mantle convection scale (Yamato et al., 2013). For the thermal part, this code uses the formulation described and tested in Duprat-Oualid et al. (2013). The evolution of the temperature $T$ through time $t$ is obtained from the heat equation (5) expressed as:

$$
\rho C p \frac{\partial T}{\partial t}=\frac{\partial}{\partial x}\left(k \frac{\partial T}{\partial x}\right)+\frac{\partial}{\partial z}\left(k \frac{\partial T}{\partial z}\right)+Q,
$$

where $C p, k$ and $Q$ correspond to the heat capacity, thermal conductivity and heat production, respectively. This equation is discretized on the nodes of the Eulerian grid and solved using an implicit finite difference method. The computed temperature is then interpolated on markers and advected following the velocity field.

At each time step, the physical material properties as well as the temperature, defined on markers, move forward in time using a $4^{\text {th }}$ order Runge-Kutta scheme. The thermal dependence of the viscosity and density is then applied to the markers. The viscosity is computed following Blankenbach et al. (1989), such as:

$$
\eta=\eta_{0} \cdot \exp \left(-\frac{b\left(T-T_{0}\right)}{\Delta T}+\frac{c(1-z)}{h}\right),
$$

where $\eta_{0}$ is the reference viscosity (at $T=T_{0}$, the surface temperature) and $\Delta T$ is the temperature difference between the bottom and the top of the model domain (see Table 1). The viscosity thus depends on temperature $T$ and depth $z$, as defined in Blankenbach et al. (1989), $b$ and $c$ being constants (see Table 1) and $h$ corresponding to the size of the model in the $z$-direction. We use the Boussinesq approximation and the density is computed as:

$$
\rho=\rho_{0}\left(1-\alpha_{v} \cdot T\right),
$$

Our model is designed to mimic the evolution of the $S W I R$, yet in more generic sense. It is therefore simplified and two-dimensional (fig. 5). The mantle convects within a $10000 \mathrm{~km}$ wide and $3000 \mathrm{~km}$ deep 
Cartesian box. The material is Newtonian and temperature and depth dependent, such that

$$
\begin{array}{ll}
\eta=f(T, z), \text { see eq. }(6) ; & \text { for } T>1300^{\circ} \mathrm{C} \\
\eta=10^{23} \mathrm{Pas} ; & \text { for } T<1300^{\circ} \mathrm{C}
\end{array}
$$

The temperature threshold for $T<1300^{\circ} \mathrm{C}$ mimics the formation of the thermal boundary layer. In addition, a continental lithosphere is represented by a $7500 \mathrm{~km}$ wide, $150 \mathrm{~km}$ thick neutrally buoyant unit (its density is that of the mantle) at high viscosity (set to $10^{25} \mathrm{~Pa} s$ to ensure minor strain) that rests atop the convecting mantle. The mechanical boundary conditions are free slip at all boundaries. Thermal boundary conditions impose a temperature drop $\Delta T$ of $3000^{\circ} \mathrm{C}$ across the mantle thickness $\left(0^{\circ} \mathrm{C}\right.$ at the surface and $3000^{\circ} \mathrm{C}$ at the core-mantle boundary), no lateral heat flow across the right and left side boundaries and a basal heat flow set to a uniform $100 \mathrm{~mW} \mathrm{~m}^{-2}$ excepted a the bottom right corner, where it is arbitrarily twice as high. This increased heat flow over $50 \mathrm{~km}$ on the bottom right is designed to polarize the convective cell by focusing the upwellings below the spreading ridge, in accord with observations of ridges that are broadly located above active mantle upwellings (e.g. Alvarez, 1982; Husson et al., 2012). The thermal regime is dictated by a heat production at depth (away from the ridge) to avoid ridge-scale processes that are beyond our scope. The bulk production is set to compare to oceanic surface values (e.g. Pollack et al., 1993). Heat capacity $C p$ is set to $1250 \mathrm{~J}_{\mathrm{kg}}^{-1} \cdot \mathrm{K}^{-} 1$ in the whole model domain and conductivities are set to $5 \mathrm{~W} \cdot \mathrm{m}^{-1} \cdot \mathrm{K}^{-1}$ and $2.63 \mathrm{~W} \cdot \mathrm{m}^{-1} \cdot \mathrm{K}^{-1}$ for the mantle and the continental lithosphere, respectively. These values ensure that our model runs under standard conditions for the Rayleigh number $R a_{0}=10^{6}$ and the Biot number $B=10$ (e.g. Grigné et al., 2007).

The initial rheological and density fields are dictated by the initial temperature field that is obtained after solving for the heat and Stokes equations in our model iteratively until a statistically convergent temperature field is achieved (after $\sim 2 \mathrm{Ga}$ ). In order to do so, this precursor episode allows for free slip at the surface but artificially replaces the continent to its initial location throughout, at each time step. The initial temperature field in our model (fig. 5) is given by the time averaged temperature field over the last 500 Myrs of this prior simulation. It allows for a statistically valid steady state thermal regime to be defined at all locations, including an upwelling underneath the proto-ridge (that corresponds to the thermal field just before continental breakup), an oceanic lithosphere on the left hand side of the continent that eventually subducts and forms a downwelling down to the core-mantle boundary, a thermal lid defined by the continent itself, drifting leftward under the action of the underlying mantle flow.

This initial configuration therefore resembles the situation just prior to continental breakup, making the continent free to drift over its convection cell. It is pulled by a downwelling (to the left), pushed by an upwelling (to the right) and dragged by the flowing mantle (below). This setup permits to monitor the 
evolution of the mantle temperature, viscosity and density fields during the journey of the continent over its convection cell, until and after the collision with the left hand side boundary. As such, this scenario can be regarded as a simplified model for the subduction of the Tethys, the Alpine collision and the African superplume. On the right-hand side, it thus compares to the evolution of the $S W I R$, from the separation between the Antarctic continent until the collision of Africa with Eurasia and thereafter, but also to any ridge whose spreading tendency is impeded on the far-field (as for instance the South Atlantic, Silver et al., 1998; Husson et al., 2012).

\subsection{Results}

The temporal evolution of our experiment is depicted by the stream function and viscosity field (fig. 6 ). The initial stage (until $\sim 25$ Myrs) correspond to the achievement of a statistical steady state of the spreading regime and to the early development of the ridge, until half-spreading rates achieve $\sim 125 \mathrm{~mm} / \mathrm{yr}$ (fig 7). During a second stage, the rates further increase, yet slowly, to almost $140 \mathrm{~mm} / \mathrm{yr}$ at $100 \mathrm{Myrs}$ (model time). This increase results from the increasing pull of the subducting plate on the left hand side (fig. 6). The model enters a third phase as the continent approaches the left boundary of the box. Because of its positive buoyancy, the continent resists subduction and enters a collisional mode; because of its high viscosity, strain rates are low; this gradually impedes further leftward migration of the continent, which almost remains stationary throughout. The developing oceanic plate between the continent and the ridge and the underlying mantle drag also undergoes compression but neither deforms for it is also highly viscous. Under these conditions, spreading rates quickly collapse to very low values until $\sim 175$ Myrs. The model then enters its last phase, where half-spreading rates are on the order of $1 \mathrm{~mm} / \mathrm{yr}$ (note that this rate scales with the viscosity and thicknesses of the oceanic and continental plates and could be adjusted accordingly). This values keeps decreasing with time until the end of the model (fig. 7) as the oceanic plate cools and thickens (fig. 6), thereby offering a growing resistance to the mantle driven compression.

The evolving motion of the plates exert an impact on the underlying mantle flow. Fundamentally, it completely changes the upper kinematic boundary condition from a mobile lid convection regime to an almost stagnant lid regime. During the transition between the two, the underlying mantle circulation is entirely remodeled. While the early stages are characterized by a well defined, single convection cell (fig. 6a-c), the flow is disrupted during the final stages by the collision of the continent on the left hand side of the model, and multiple cells arise (fig. 6c-e). Importantly, these cells are transient, and their short-lasting nature is partially controlled by a growing number of thermally buoyant plumes. This reorganization has a significant impact on mantle stirring and heat advection underneath the ridge, for the most proximal convective cell to the spreading ridge alternates periods of vigorous upwelling driven by actively rising mantle plumes (as at 200 Myrs, fig. 6d) and periods of relative quiescence during which the mantle underneath the 
ridge is virtually ignored by the convective field (as at 250 Myrs, fig. 6e). On average during this period, the sub-lithospheric mantle below the ridge is less vigorously stirred than during the pre-collisional stage (see full length movie of the stream function online).

The thermal structure of both the mantle and the lithosphere is seriously impacted on the long-term. During the pre-collisional stage (25-100 Myrs), the oceanic lithosphere that forms on the right hand side of the model evolves according to the half-space cooling model (fig. 8a). It gently grows and the heat flow at the ridge decreases down to a nearly stationary value of $\sim 100 \mathrm{~mW}^{-2}$ at $\sim 75$ Myrs (fig. 7). (Note that our simplified setup is not designed to comprehensively reproduce the thermal structure of the ridge itself: the flow and temperature fields are mostly dictated by a temperature dependent rheology, that doesn't account for ridge-scale processes like melt extraction; this simplification explains the rather long period of decreasing heat flow (0-75 Myrs) before steady state is reached at the local scale). Once collision initiates (from 100 Myrs onwards), spreading rates decrease and the structure of the oceanic lithosphere gradually departs from a that of a steady half-space cooling model (fig. 8b). First, because the flow partly deserts the mantle wedge below the ridge, the post-collisional convective regime advects less heat underneath the ridge. Consequently, the expanding oceanic plate overall thickens and cools down at a faster rate than during the pre-collisional stage. Between 120 and 180 Myrs, the heat flow drops accordingly and settle to some 50\% of the pre-collisional heat flow (fig. 7). Second, local gravitational instabilities are excited by the increasingly chaotic convective regime. The thermal structure of the oceanic lithosphere consequently degrades and departs from that of the half-space cooling model (fig. 8 and supplementary online material). The gravitational instabilities that increasingly alter the structure of the lithosphere in the post-collisional phase make its thickness vary in time and space, and the sub-lithospheric temperature be alternatively higher or colder than if it were dictated by the half-space cooling model. This evolution -thickening of the lithospheric lid and loss of its coherent structure- resembles the thermal structure inferred form seismic tomography (fig. 3 ); the variable spreading rates of the ridges at present-day thus represent different stages in the transition scenario between mobile lid to stagnant lid.

The similarity between the model and observations from seismic tomography also holds for the vertical temperature profile underneath the lithosphere: modeled temperature vary with the greatest amount at shallow depths ( $\sim 70-80 \mathrm{~km}$, fig. 9$)$, and wave speed heterogeneities are accordingly largest in the sublithospheric mantle at similar depths (figs. 3 and $4 \mathrm{~b}$ ). This suggests that the temperature variations that are induced by the changing boundary conditions are mostly located at shallow depths, i.e. at the most appropriate depth to control the melt supply. The temperature field in the first $100 \mathrm{~km}$ prominently controls the melting, and its evolution can be tracked by the depths of reference isotherms $\left(1100^{\circ} \mathrm{C}\right.$ and $1300^{\circ} \mathrm{C}$, fig. 9a), that abruptly drop by $50 \%$ during the transient stage that follows the onset of collision, between 
120 and 180 Myrs, before settling to $\sim 50 \mathrm{~km}\left(1100^{\circ} \mathrm{C}\right)$ or $\sim 60 \mathrm{~km}\left(1300^{\circ} \mathrm{C}\right)$. This cooling event of the sublithospheric mantle is similarly depicted by the temperature at a constant depth underneath the ridge (typically between 70 and $80 \mathrm{~km}$, fig. 9b), that decrease by some $200^{\circ} \mathrm{C}$. The thermal evolution of the sublithospheric temperature is dictated by the competition between heat advection from the deeper mantle and conduction towards the surface. Our models suggests that lower heat advection -and not a higher conductivity- is responsible for a decrease in the potential temperature. Yet, our results do not rule out alternative mechanisms, such as variable hydrothermal cooling (Phipps Morgan and Chen, 1993), but suggest that a weakened heat advection from a slower convective regime that ignores the upper mantle is enough to cool down slow spreading ridges at a fast rate.

\section{Discussion}

Our interpretation of the seismic tomography in terms of thermal structure of spreading lithosphere suggest that it is the heat supply from the mantle, being modulated by plate tectonics, that permits -or notsufficient melting to grow a standard, $7 \mathrm{~km}$ thick, oceanic crust. Our thermal mechanical model confirms this hypothesis, by showing that the upper kinematic conditions (mobile lid vs. stagnant lid) control the convective regime of the mantle, and therefore the heat supply to the mantle that melts beneath the ridges. More specifically, our model can be confronted to a variety of independent observables, that in turn allow for a quantification of the process at play.

The melt productivity at oceanic ridges is key diagnostic of the mantle temperature underneath the ridge (Klein and Langmuir, 1987; Shen and Forsyth, 1995), and corresponds to crustal thickness. The higher the mantle temperature the more profuse partial melting is, and the thicker the crust. Our model suggests that for a typical melting depth of $70-80 \mathrm{~km}$, the temperature is lower by $\sim 200^{\circ} \mathrm{C}$ in the stagnant lid (or postcollisional) regime than in the mobile lid (pre-collisional) regime (fig. 9a). Along the same lines, the depth of the isotherms $1100-1300^{\circ} \mathrm{C}$ increases by $\sim 20 \mathrm{~km}$, which further refrains the melting capacity (fig. 9b). Such a weakening of the thermal regime, which corresponds to the entire range of inferred temperatures in the samples of the present day mid-oceanic ridge system, is unambiguously sufficient to decrease the extent of partial melting and starve the ridge from the magmatic supply -at least partially, if not entirely. As an example, following the model of Klein and Langmuir (1987), we estimate that for such a temperature decrease, the partial melt would drop from $\sim 13.5 \%$ to less than $\sim 5 \%$, which corresponds to a decrease in crustal thickness from $\sim 11 \mathrm{~km}$ to less than $2 \mathrm{~km}$. Such a thin crustal thickness is comparable to the estimates of partial melt and crustal thickness derived from the basalt chemistry or geophysical data collected in the deepest sections of the SWIR and Gakkel ridges (Cannat, 1993; Jokat and Schmidt-Aursch, 2007; Michael 
et al., 2003; Cannat et al., 2008; Standish et al., 2008). In addition, the surface heat flow at the ridge is also diagnostic of the same process, and our model predictions suggest a decrease in heat flow by $40 \mathrm{~mW} \mathrm{~m} \mathrm{~m}^{-2}$ (fig. 7), compatible with the extrapolations of direct measurements (Pollack et al., 1993; Davies, 2013) that possibly suggest that slow ridges are some 50 to $100 \%$ colder than fast spreading ridges, although ultraslow ridges in particular are poorly documented.

In turn, it follows that the sublithospheric mantle field, modified by the evolving global convective pattern, likely controls the chemistry of ridge basalts, which in turn could not strictly be used as a probe to infer the deep mantle potential temperature.

Following our predictions, one should expect that partial melting was overall higher in the past and a thicker crust associated with the fast spreading episode of the SWIR, before the onset of the African-Europe collision in the late Eocene. This can in principle be tested from the chemical composition of ancient seafloor basalts (as proposed by Humler et al., 1999; Fisk and Kelley, 2002; Brandl et al., 2013). Unfortunately available samples do not allow to generate high resolution transects orthogonally to the ridge to unravel such temporal variations in mantle temperatures. Nonetheless, from a global perspective, the chemical composition of ancient seafloor basalts reveal anomalously hot mantle temperatures prior to $80 \mathrm{Ma}$ (for the Atlantic and Indian oceans, but not for the Pacific; Humler et al., 1999; Fisk and Kelley, 2002; Brandl et al., 2013). Because continents act as thermal lids and raise their sub-lithospheric temperatures by $\sim 100^{\circ} \mathrm{C}$ with respect to the oceanic counterparts (Grigné and Labrosse, 2001; Lenardic et al., 2005; Coltice et al., 2007), this observation was at first related to the effect of continental insulation (Humler and Besse, 2002). But the case of the ultraslow Gakkel ridge, which remains cool regardless of its proximity to the continents (Humler et al., 1999), jeopardizes this interpretation. Our model provides an alternative explanation that reconciles these observations, as our results indicate that the mantle thermal heterogeneities sampled by mid-oceanic ridges also responds efficiently to the feedback interaction between surface tectonics and mantle convection, that may even overcome sub-continental heating.

Last, the model-predicted structure of the lithosphere is consistent with our observations of the global Swave seismic tomography model of Debayle and Ricard (2012): the transition from the mobile lid to stagnant lid regime is accompanied by a decrease in the spreading rates and by a loss in the coherency of the thermal structure of the lithosphere. Indeed, both the thermo-mechanical model (fig. 8) and the observations of the seismic tomography (fig. 3) show that the geometry of freely spreading ridges satisfactorily reproduce the half-space cooling model until spreading is blocked at the far field boundaries. Gravitational instabilities then tend to develop and the lithospheric lid thickens underneath slow-spreading plates (fig. 6). The loss in the structural coherency of the developing oceanic lithosphere and subsequent destabilization is partly 
triggered by the increasing emergence of small scale, short lived thermal plumes during the post-collisional stage. In our model, their number increases in the stagnant lid regime. In real Earth, oceanic plates are riddled by plumes that accompany mantle upwellings (Boschi et al., 2007; Husson and Conrad, 2012). Their surface expression in the abysses is however difficult to decipher, and seamounts may be considered as the best available proxy for the distribution of submarine volcanism (see compilations by Kitchingman and Lai, 2004; Hillier and Watts, 2007). If seamounts actually owe their existence to mantle plumes, one can easily conclude from their apparent spatial distribution -only apparent because it is inferred from unevenly spaced ship tracks- that mantle plumes are much more frequent in the vicinity of slow or ultraslow spreading ridges than elsewhere (see Supplementary Information). This observation shall not be taken as a supporting evidence of our model but instead as a highly compatible observation that further links our model to independent features, and that may suggest that the mantle flow is more chaotic underneath slow- and ultraslow spreading ridges.

Similarly, the fact that the mantle is more chaotic underneath slow spreading ridges is furthermore documented by the chemistry of basalts, that is -conformably to crustal thickness- remarkably uniform for spreading rates higher then $15 \mathrm{~mm} / \mathrm{yr}$, and much more heterogeneous for slower spreading rates (White et al., 1992; Bown and White, 1994). The thermo-chemical regime underneath the mantle certainly controls the melting and mixing processes (e.g. Klein and Langmuir, 1987). Yet, our model provides an alternative explanation, as it suggests that the mantle underneath slow-spreading centers would be sampled from multiple sources at different locations in the mantle (fig. 6), these sources possibly having different compositions. Conversely, the stable pattern of mantle circulation underneath fast spreading ridges only allows for the sampling of a unique reservoir in the upwelling mantle, preventing any heterogeneous signal. Note that this observation doesn't imply that the mantle is less efficiently stirred underneath slow spreading ridges, or that the temperature varies so as to generate incomplete melts, but instead that the chemical heterogeneity of those ridges owes its existence to a more chaotic sampling of the mantle than elsewhere.

\section{Conclusions}

Current spreading rates vary from as much as $150 \mathrm{~mm} / \mathrm{yr}$ in the fast East Pacific rise to almost null values in some segments of the North Atlantic- Arctic system (Gakkel ridge), the entire range of velocities being measured in between, and spreading rates have varied in the past (see the maps of Müller et al., 2008). Based on our observations, reinforced by the results from our model, we suggest that these rates are modulated by plate tectonics at the far field tectonics forces more than by the vigor of the underlying mantle flow. The kinematics of ridges is driven by the competition between the global convective system and crustal tectonics, as it is the case for subduction zones (Husson, 2012). 
Our model depicts the genetic relationships between far-field tectonics and mantle flow during the transition from free continental drift to continental collision, and emphasizes that a unique mechanism build mountain belts in the far field, compresses the plates at the surface (Yamato et al., 2013), and controls the spreading rates of mid-oceanic ridges. The feedback interaction of the coupled system alters the dynamics of the system by changing the surface boundary condition, from a free slip regime toward a no slip regime. During this transition, the circulation of the mantle is drastically modified: while during the pre-collisional stage, it is characterized by a stationary single convection cell, the post-collisional stage features multiple convection cells that partially ignore the mantle wedge underneath the spreading ridges. The thermal incidence of this remodeled mantle dynamics is primordial, for it advects less heat underneath the ridge. The mantle there cools down, and consequently, lower amounts of partial melt are expected at ultraslow spreading ridges. Interestingly, both the model and the seismic structure of the mantle underneath ridges reveal that most of the variations in the thermal field are found at shallow depths, where it behaves as an extremely efficient control on the melt supply at ridges.

Our experiment therefore validates, or at least reveal the plausibility, of the hypothesized chain of relationships that we anticipated based on observations of the $S W I R$ and Gakkel ridge. It is far-field tectonics that causes the starvation of basaltic melt underneath ultraslow spreading ridges. In the current model, collision is at play and alters the dynamics and thermal evolution of the mantle, but we emphasize that this model could be expanded to any ridge whose spreading tendency is restrained by far-field forces (as for instance the South Altantic, Silver et al., 1998; Husson et al., 2012).

Finally, the joint analysis of the model and observations reveals that the regime of mantle convection drastically changes when the system is sufficiently blocked at the far ends to enter the stagnant lid regime, when ridges spread in the ultraslow regime, below $15 \mathrm{~mm} / \mathrm{yr}$ (Reid and Jackson, 1981). We find that his threshold corresponds to the change in the magmatic supply of course, but also in the thermal structure of the lithosphere, as inferred from seismic tomography, heat flow, or ridge bathymetry, and clearly departs from the half-space cooling model below this threshold. These results support the idea that ultraslow ridges legitimately deserve the status of being a specific class of spreading ridges (Dick et al., 2003). Above that threshold, mantle flow doesn't seem to adjust to the rate of spreading, as the single-cell regime dominates. This conclusion is not drawn from our model but also from the observation that melting linearly adjust to spreading rates so as to grow a $7 \mathrm{~km}$ crust, suggesting that above a spreading rate of $15 \mathrm{~mm} / \mathrm{yr}$, the dynamic evolution of ridges is controlled by lithospheric processes more than deeper mantle convection. However, regardless of this first order distinction, other observations and model results indicate that slow and fast spreading ridges also belong to different classes: the thermal structure of slow ridges is less well structured, 
their oceanic lithospheres are marked by a greater amount of seamounts, and short living plumes erode and corrupt their thermal structures.

\section{Acknowledgements}

P.Y. thank P. Tackley and D. May for material support (ETH Brutus cluster). Comments from two anonymous reviewers greatly improved the manuscript. Thanks to E. Debayle for sharing his model. Many maps and plots were designed using the GMT (Generic Mapping Tools) software package (Wessel and Smith, 1991).

\section{References}

Alvarez, W., 1982. Geological evidence for the geographical pattern of mantle return flow and the driving mechanism of plate tectonics. Journal of Geophysical Research: Solid Earth 87 (B8), 6697-6710.

URL http://dx.doi.org/10.1029/JB087iB08p06697

Blankenbach, B., Busse, F., Christensen, U., Cserepes, L., Gunkel, D., Hansen, U., Harder, H., Jarvis, G., Koch, M., Marquart, G., Moore, D., Olson, P., Schmeling, H., Schnaubelt, T., Jul. 1989. A benchmark comparison for mantle convection codes. Geophysical Journal International 98, 23-38.

Boschi, L., Becker, T. W., Steinberger, B., Oct. 2007. Mantle plumes: Dynamic models and seismic images. Geochemistry, Geophysics, Geosystems 8, 10006.

Bown, J. W., White, R. S., Feb. 1994. Variation with spreading rate of oceanic crustal thickness and geochemistry. Earth and Planetary Science Letters 121, 435-449.

Brandl, P. A., Regelous, M., Beier, C., Haase, K. M., May 2013. High mantle temperatures following rifting caused by continental insulation. Nature Geoscience 6, 391-394.

Cannat, M., Mar. 1993. Emplacement of mantle rocks in the seafloor at mid-ocean ridges. Journal of Geophysical Research 98, $4163-4172$.

Cannat, M., Sauter, D., Bezos, A., Meyzen, C., Humler, E., Le Rigoleur, M., Apr. 2008. Spreading rate, spreading obliquity, and melt supply at the ultraslow spreading Southwest Indian Ridge. Geochemistry, Geophysics, Geosystems 9, 4002.

Chen, Y., Morgan, W. J., 1990. Rift valley/no rift valley transition at mid-ocean ridges. Journal of Geophysical Research: Solid Earth 95 (B11), 17571-17581.

URL http://dx.doi.org/10.1029/JB095iB11p17571

Chen, Y. J., Apr. 1992. Oceanic crustal thickness versus spreading rate. Geophysical Research Letters 19, 753-756.

Coltice, N., Phillips, B. R., Bertrand, H., Ricard, Y., Rey, P., May 2007. Global warming of the mantle at the origin of flood basalts over supercontinents. Geology 35, 391.

Curewitz, D., Karson, J. A., 1998. Geological consequences of dike intrusion at mid-ocean ridge spreading centers. Washington DC American Geophysical Union Geophysical Monograph Series 106, 117-136.

Davies, J. H., Oct. 2013. Global map of solid Earth surface heat flow. Geochemistry, Geophysics, Geosystems 14, 4608-4622.

Debayle, E., Ricard, Y., Oct. 2012. A global shear velocity model of the upper mantle from fundamental and higher Rayleigh mode measurements. Journal of Geophysical Research (Solid Earth) 117, 10308.

Debayle, E., Ricard, Y., Aug. 2013. Seismic observations of large-scale deformation at the bottom of fast-moving plates. Earth and Planetary Science Letters 376, 165-177. 
DeMets, C., Gordon, R. G., Argus, D. F., Stein, S., 1994. Effect of recent revisions to the geomagnetic reversal time scale on estimates of current plate motions. Geophysical Research Letters 21, 2191-2194.

Dewey, J. F., Helman, M. L., Knott, S. D., Turco, E., Hutton, D. H. W., Jan. 1989. Kinematics of the western Mediterranean. Geological Society of London Special Publications 45, 265-283.

Dick, H. J. B., Lin, J., Schouten, H., Nov. 2003. An ultraslow-spreading class of ocean ridge. Nature 426, 405-412.

Duprat-Oualid, S., Yamato, P., Pitra, P., Nov. 2013. Major role of shear heating in intracontinental inverted metamorphism: Inference from a thermo-kinematic parametric study. Tectonophysics $608,812-831$.

Fisk, M., Kelley, K. A., Sep. 2002. Probing the Pacific's oldest MORB glass: mantle chemistry and melting conditions during the birth of the Pacific Plate. Earth and Planetary Science Letters 202, 741-752.

Forte, A. M., Quéré, S., Moucha, R., Simmons, N. A., Grand, S. P., Mitrovica, J. X., Rowley, D. B., Jul. 2010. Joint seismicgeodynamic-mineral physical modelling of African geodynamics: A reconciliation of deep-mantle convection with surface geophysical constraints. Earth and Planetary Science Letters 295, 329-341.

Fox, C. G., Radford, W. E., Dziak, R. P., Lau, T.-K., Matsumoto, H., Schreiner, A. E., Jan. 1995. Acoustic detection of a seafloor spreading episode on the Juan de Fuca Ridge using military hydrophone arrays. Geophysical Research Letters 22, $131-134$

Gerya, T. V., Yuen, D. A., Jul. 2003. Rayleigh-Taylor instabilities from hydration and melting propel 'cold plumes' at subduction zones. Earth and Planetary Science Letters 212, 47-62.

Gerya, T. V., Yuen, D. A., Aug. 2007. Robust characteristics method for modelling multiphase visco-elasto-plastic thermomechanical problems. Physics of the Earth and Planetary Interiors 163, 83-105.

Grigné, C., Labrosse, S., 2001. Effects of continents on Earth cooling: Thermal blanketing and depletion in radioactive elements. Geophysical Research Letters 28, 2707-2710.

Grigné, C., Labrosse, S., Tackley, P. J., Aug. 2007. Convection under a lid of finite conductivity: Heat flux scaling and application to continents. Journal of Geophysical Research (Solid Earth) 112, 8402.

Hillier, J. K., Watts, A. B., Jul. 2007. Global distribution of seamounts from ship-track bathymetry data. Geophysical Research Letters 34, 13304 .

Humler, E., Besse, J., Oct. 2002. A correlation between mid-ocean-ridge basalt chemistry and distance to continents. Nature $419,607-609$.

Humler, E., Langmuir, C., Daux, V., 1999. Depth versus age: new perspectives from the chemical compositions of ancient crust. Earth and Planetary Science Letters $173(1-2), 7-23$.

URL http://www.sciencedirect.com/science/article/pii/S0012821X99002186

Humler, E., Thirot, J. L., Montagner, J. P., Jul. 1993. Global correlations of mid-ocean-ridge basalt chemistry with seismic tomographic images. Nature 364, 225-228.

Husson, L., Dec. 2012. Trench migration and upper plate strain over a convecting mantle. Physics of the Earth and Planetary Interiors $212,32-43$.

Husson, L., Conrad, C. P., Sep. 2012. On the location of hotspots in the framework of mantle convection. Geophysical Research Letters 39, 17304.

Husson, L., Conrad, C. P., Faccenna, C., Feb. 2012. Plate motions, Andean orogeny, and volcanism above the South Atlantic convection cell. Earth and Planetary Science Letters 317, 126-135.

Jokat, W., Schmidt-Aursch, M. C., Mar. 2007. Geophysical characteristics of the ultraslow spreading Gakkel Ridge, Arctic Ocean. Geophysical Journal International 168, 983-998.

Kitchingman, A., Lai, S., 2004. Inferences on potential seamount locations from mid-resolution bathymetric data. Fisheries Centre Research Reports 12 (5), 7-12.

Klein, E. M., Langmuir, C. H., Jul. 1987. Global correlations of ocean ridge basalt chemistry with axial depth and crustal 
thickness. Journal of Geophysical Research 92, 8089-8115.

Kreemer, C., Oct. 2009. Absolute plate motions constrained by shear wave splitting orientations with implications for hot spot motions and mantle flow. Journal of Geophysical Research (Solid Earth) 114, 10405.

Lenardic, A., Moresi, L.-N., Jellinek, A. M., Manga, M., Jun. 2005. Continental insulation, mantle cooling, and the surface area of oceans and continents [rapid communication]. Earth and Planetary Science Letters 234, 317-333.

Lithgow-Bertelloni, C., Silver, P. G., Sep. 1998. Dynamic topography, plate driving forces and the African superswell. Nature 395, 269-272.

Michael, P. J., Langmuir, C. H., Dick, H. J. B., Snow, J. E., Goldstein, S. L., Graham, D. W., Lehnert, K., Kurras, G., Jokat, W., Mühe, R., Edmonds, H. N., Jun. 2003. Magmatic and amagmatic seafloor generation at the ultraslow-spreading Gakkel ridge, Arctic Ocean. Nature 423, 956-961.

Müller, R. D., Sdrolias, M., Gaina, C., Roest, W. R., Apr. 2008. Age, spreading rates, and spreading asymmetry of the world's ocean crust. Geochemistry, Geophysics, Geosystems 9, 4006.

Parsons, B., Sclater, J. G., Feb. 1977. An analysis of the variation of ocean floor bathymetry and heat flow with age. Journal of Geophysical Research 82, 803-827.

Phipps Morgan, J., Chen, Y. J., Apr. 1993. The genesis of oceanic crust: Magma injection, hydrothermal circulation, and crustal flow. Journal of Geophysical Research 98, 6283-6298.

Pollack, H. N., Hurter, S. J., Johnson, J. R., Aug. 1993. Heat flow from the earth's interior - Analysis of the global data set. Reviews of Geophysics 31, 267-280.

Reid, I., Jackson, H. R., Jun. 1981. Oceanic spreading rate and crustal thickness. Marine Geophysical Research 5, 165-172.

Ritzwoller, M. H., Shapiro, N. M., Zhong, S.-J., Sep. 2004. Cooling history of the Pacific lithosphere. Earth and Planetary Science Letters 226, 69-84.

Sauter, D., Sloan, H., Cannat, M., Goff, J., Patriat, P., Schaming, M., Roest, W. R., Oct. 2011. From slow to ultra-slow: How does spreading rate affect seafloor roughness and crustal thickness? Geology 39, 911-914.

Shen, Y., Forsyth, D. W., Feb. 1995. Geochemical constraints on initial and final depths of melting beneath mid-ocean ridges. Journal of Geophysical Research 100, 2211-2237.

Silver, P., Russo, R., Lithgow-Bertelloni, C., 1998. Coupling of south american and african plate motion and plate deformation. Science 279, 60-63.

Sotin, C., Parmentier, E. M., Aug. 1989. Dynamical consequences of compositional and thermal density stratification beneath spreading centers. Geophysical Research Letters 16, 835-838.

Standish, J. J., Dick, H. J. B., Michael, P. J., Melson, W. G., O'Hearn, T., May 2008. MORB generation beneath the ultraslow spreading Southwest Indian Ridge (9-25E): Major element chemistry and the importance of process versus source. Geochemistry, Geophysics, Geosystems 9, 5004.

Su, W., Mutter, C. Z., Mutter, J. C., Buck, W. R., Feb. 1994. Some theoretical predictions on the relationships among spreading rate, mantle temperature, and crustal thickness. Journal of Geophysical Research 99, 3215-3227.

Turcotte, D. L., Schubert, G., Apr. 2002. Geodynamics - 2nd Edition. Wiley.

Wessel, P., Smith, W. H. F., 1991. Free software helps map and display data. EOS Transactions 72, 441-446.

White, R. S., McKenzie, D., O’Nions, R. K., Dec. 1992. Oceanic crustal thickness from seismic measurements and rare earth element inversions. Journal of Geophysical Research 97, 19683.

Yamato, P., Husson, L., Becker, T. W., Pedoja, K., Dec. 2013. Passive margins getting squeezed in the mantle convection vice. Tectonics 32, 1559-1570.

Yamato, P., Tartèse, R., Duretz, T., May, D. A., Mar. 2012. Numerical modelling of magma transport in dykes. Tectonophysics $526,97-109$.

Zhou, H., Dick, H. J. B., Feb. 2013. Thin crust as evidence for depleted mantle supporting the Marion Rise. Nature 494, 


\begin{tabular}{|l|l|l|}
\hline Symbol & Value & Unit \\
\hline$\eta_{0}$ & $8.1 \mathrm{e} 22$ & Pa.s \\
$\rho_{0}$ & 4000 & $\mathrm{~kg} \cdot \mathrm{m}^{-3}$ \\
$T_{0}$ & 0 & ${ }^{\circ} \mathrm{C}$ \\
$\Delta T$ & 3000 & ${ }^{\circ} \mathrm{C}$ \\
$h$ & 3000 & $\mathrm{~km}$ \\
$b^{*}$ & $\log (16384)$ & - \\
$c^{*}$ & $\log (64)$ & - \\
$g$ & 10 & $m . s^{-2}$ \\
$\alpha_{v}$ & $2.5 \mathrm{e}-5$ & $K^{-1}$ \\
\hline
\end{tabular}

Table 1: Model parameters. *: from Blankenbach et al. (1989)

\section{Supplementary information}

The full lengths movies of the experiment are provided online, including the stream function and viscosity field (Sstreamvisco.m4v), full temperature field (Stempfull.m4v), and (sub-)lithosphere temperature field (Stemplith.m4v). 


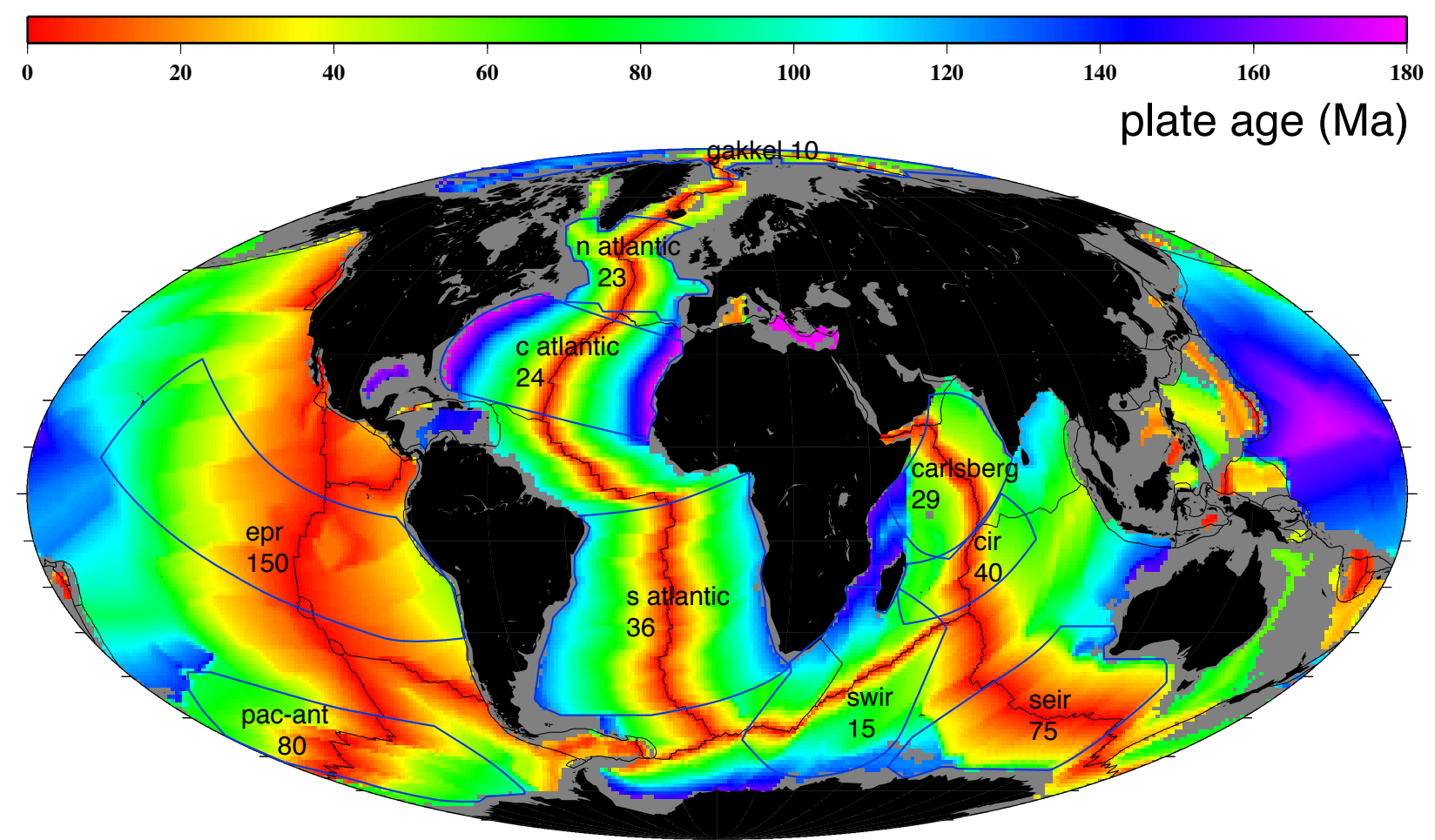

Figure 1: a) Seafloor age map (Müller et al., 2008). Ridge labels and maximum spreading rates (mm/yr). epr: East Pacific Rise (Nazca/Pacific); pac - ant: Pacific-Antarctic ridge (Pacific/Antarctic); seir: South East Indian Ridge (Australia/Antarctic); s atlantic: South Atlantic ridge (Africa/South America); carlsberg: Carlsberg ridge (Africa/India); c atlantic: Central Atlantic ridge (North America/Africa); $n$ atlantic: North Atlantic ridge (Eurasia/North America); swir: South West Indian Ridge (Antarctic/Africa); gakkel: Gakkel ridge (Eurasia/North America). Blue contours delineate the location of the oceanic domains considered for oceanic plate pairs across ridges. 


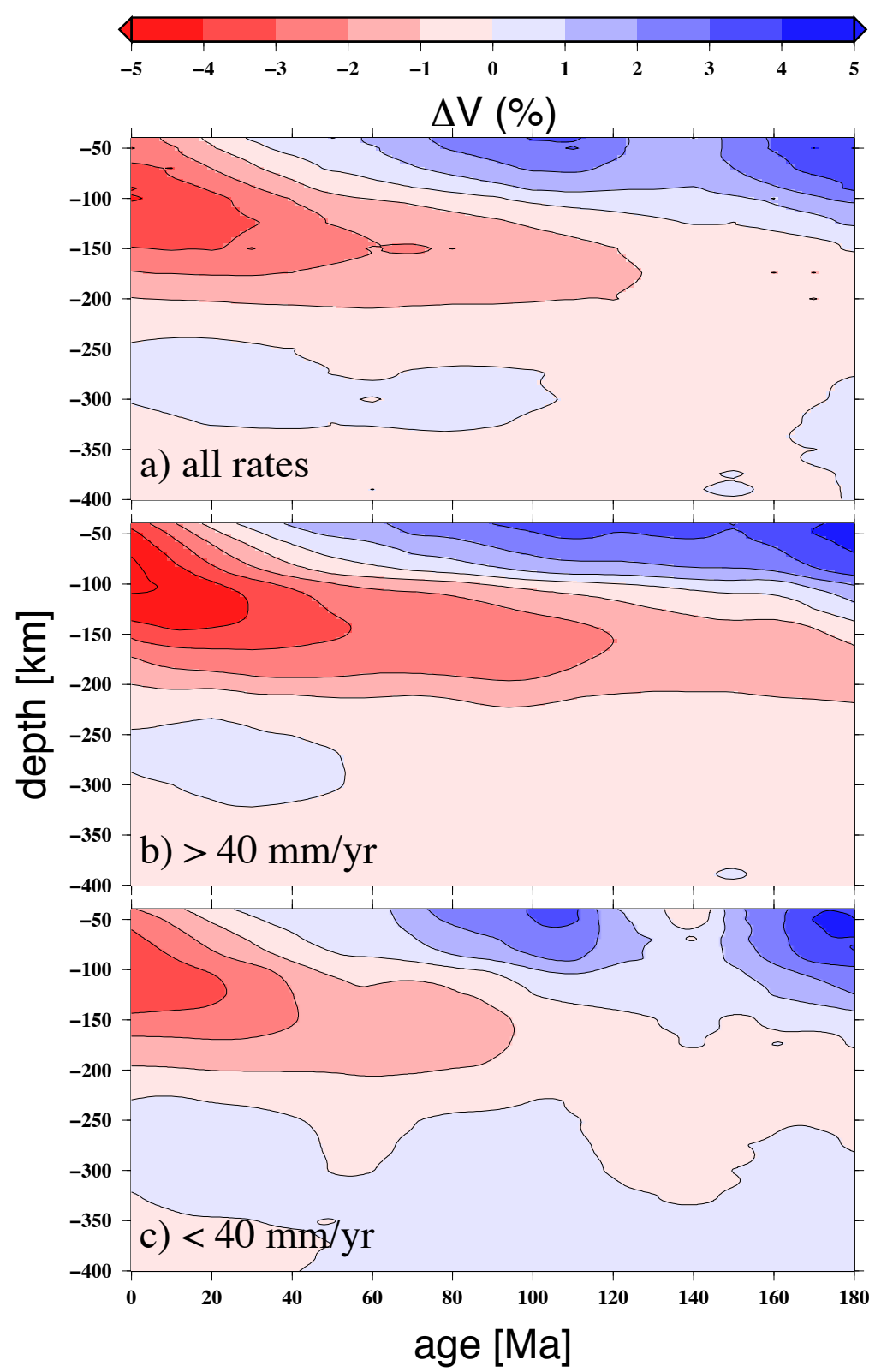

Figure 2: Synthetic cross-sections across the $S$ wave tomographic model of Debayle and Ricard (2012) for all oceanic plates, sampled at all locations (a) and where the absolute motion is faster (b) and slower (c) than $40 \mathrm{~mm} / \mathrm{yr}$ (plate motion from Kreemer, 2009). Color scale indicates the wave speed anomalies (in \%) with respect to their reference model. 


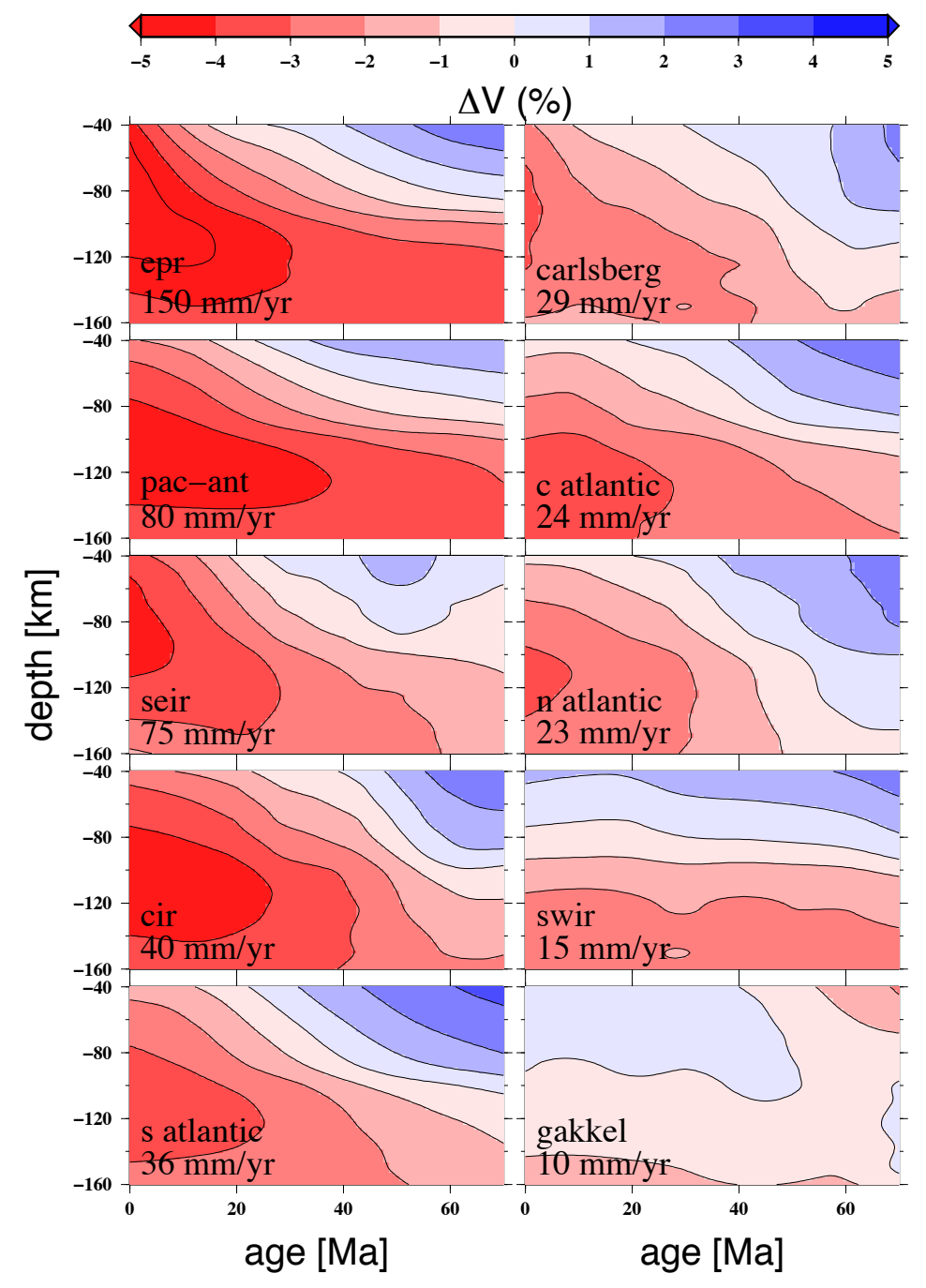

Figure 3: Synthetic cross-sections across the $S$ wave tomographic model of Debayle and Ricard (2012) for oceanic plate pairs across ridges (see location fig. 1). epr: East Pacific Rise (Nazca/Pacific); pac - ant: Pacific-Antarctic ridge (Pacific/Antarctic); seir: South East Indian Ridge (Australia/Antarctic); s atlantic: South Atlantic ridge (Africa/South America); carlsberg: Carlsberg ridge (Africa/India); c atlantic: Central Atlantic ridge (North America/Africa); $n$ atlantic: North Atlantic ridge (Eurasia/North America); swir: South West Indian Ridge (Antarctic/Africa); gakkel: Gakkel ridge (Eurasia/North America). Rates in $\mathrm{mm} / \mathrm{yr}$ are full spreading rates. 

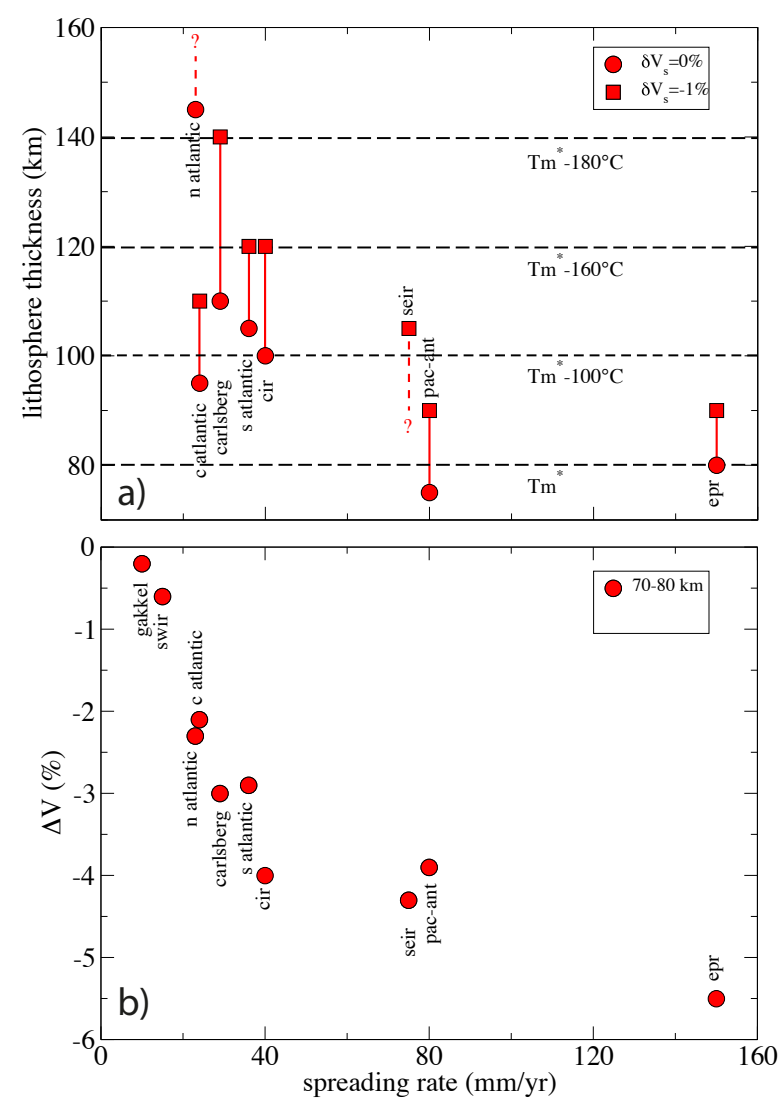

Figure 4: a) Depths of the wave speed anomalies $\delta V_{s}=0 \%$ (circles) and $\delta V_{s}=-1 \%$ (squares) underneath spreading lithospheres at 65-70 Ma (inferred from the synthetic age-depth cross-sections of oceanic plates, derived from the $S$ wave tomographic model of Debayle and Ricard, 2012, as a function of spreading rates (NUVEL1, DeMets et al., 1994), for individual spreading ridges (see fig. 3). These depths are taken as proxies for lithosphere thickness. Lithosphere thickness converts into mantle temperature, following a halfspace cooling model (e.g. Parsons and Sclater, 1977; Turcotte and Schubert, 2002). Dashed lines are abaqus showing the mantle temperature with respect to the temperature $T_{m}{ }^{\star}$ below a $80 \mathrm{~km}$ thick lithosphere. b) Magnitude of the wave speed anomalies $\delta V_{s}$ underneath the ridge, as a function of spreading rate. 


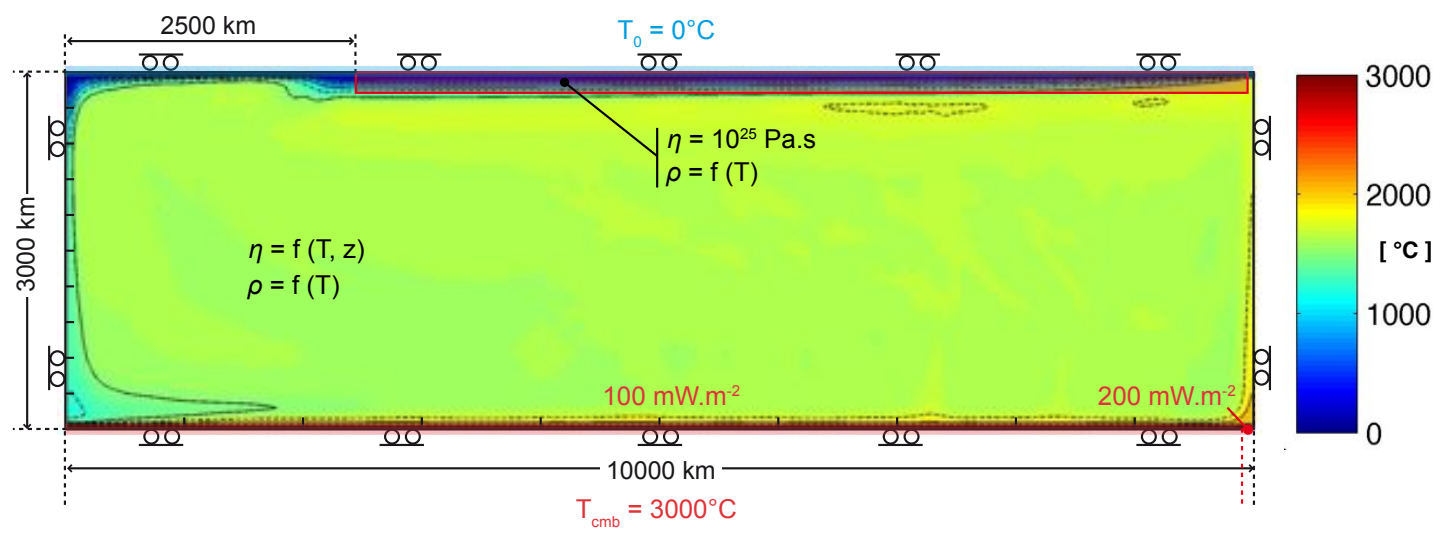

Figure 5: Model setup and initial temperature field. The red rectangle at the surface delineates the highly viscous continental lithosphere. $T_{0}$ and $T_{C M B}$ are the temperatures at the surface and the core-mantle boundary. Rollers indicates free-slip boundary conditions. See text for all details regarding the numerical scheme and initial and boundary conditions. 


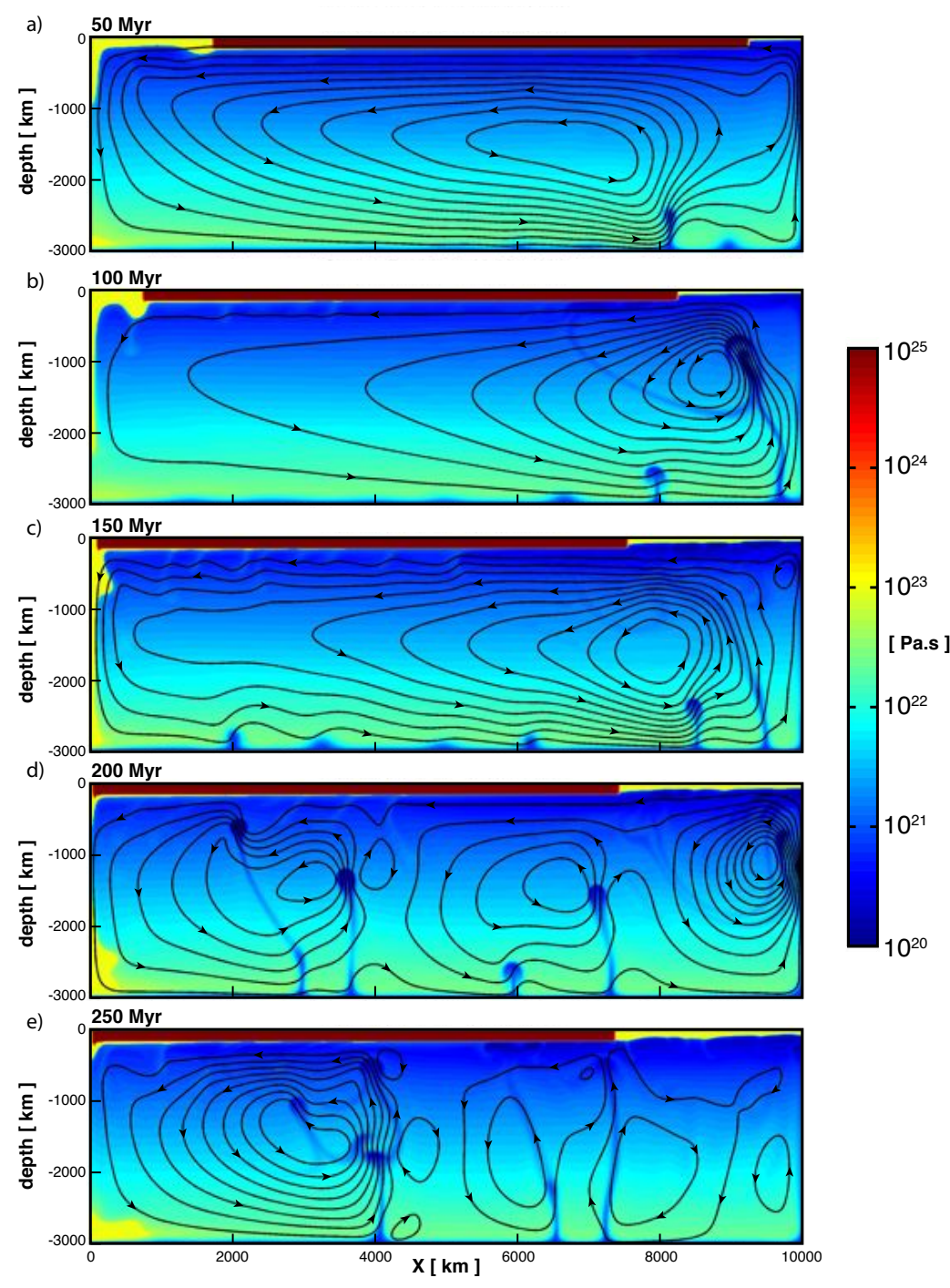

Figure 6: Stream function (curves) and viscosity field (colored background) sampled with a 50 Myrs time step. The transition from a mobile lid regime to a quasi stagnant lid regime occurs between 150 Myrs and 200 Myrs. 


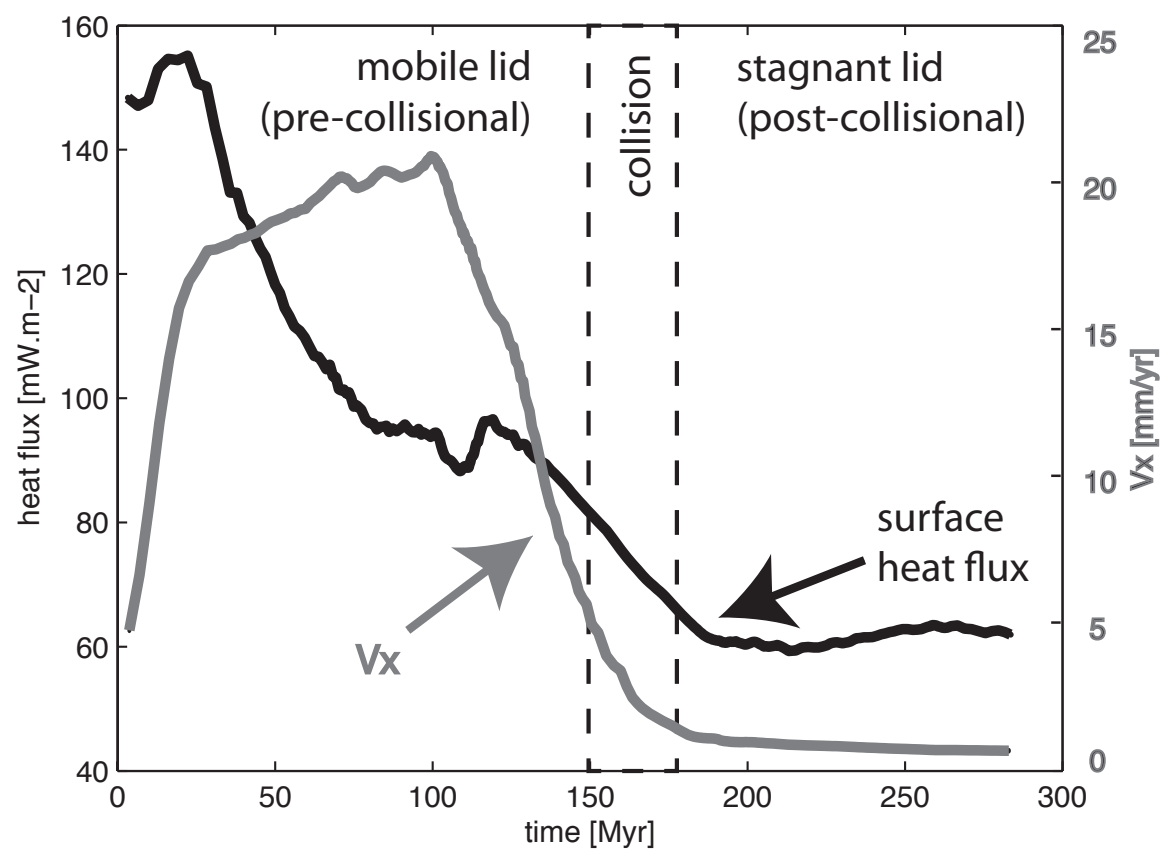

Figure 7: Modeled half-spreading rates $V_{x}$ (horizontal velocity at the ridge), and heat flux at the ridge, as a function of time. Dashed lines outline the approximate timing of collision and the transition between the mobile lid and stagnant lid regimes of mantle convection.

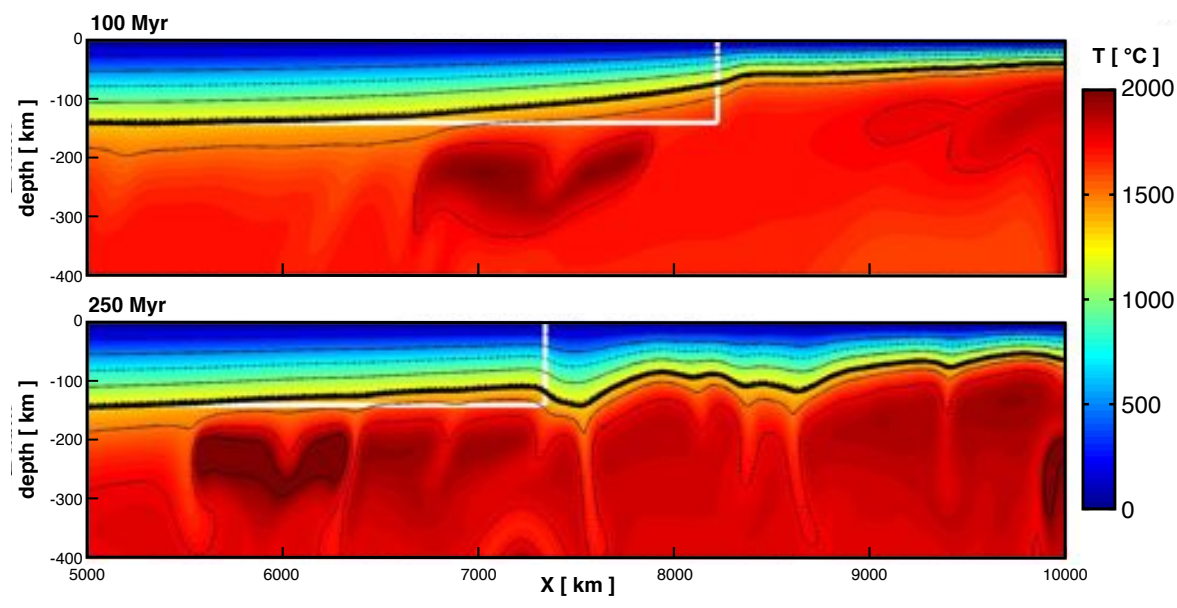

Figure 8: Temperature field in the upper mantle and lithosphere at $100 \mathrm{Ma}$ (pre-collisional stage, top) and $250 \mathrm{Ma}$ (post-collisional stage, bottom). White box delineates the continental lithosphere. 


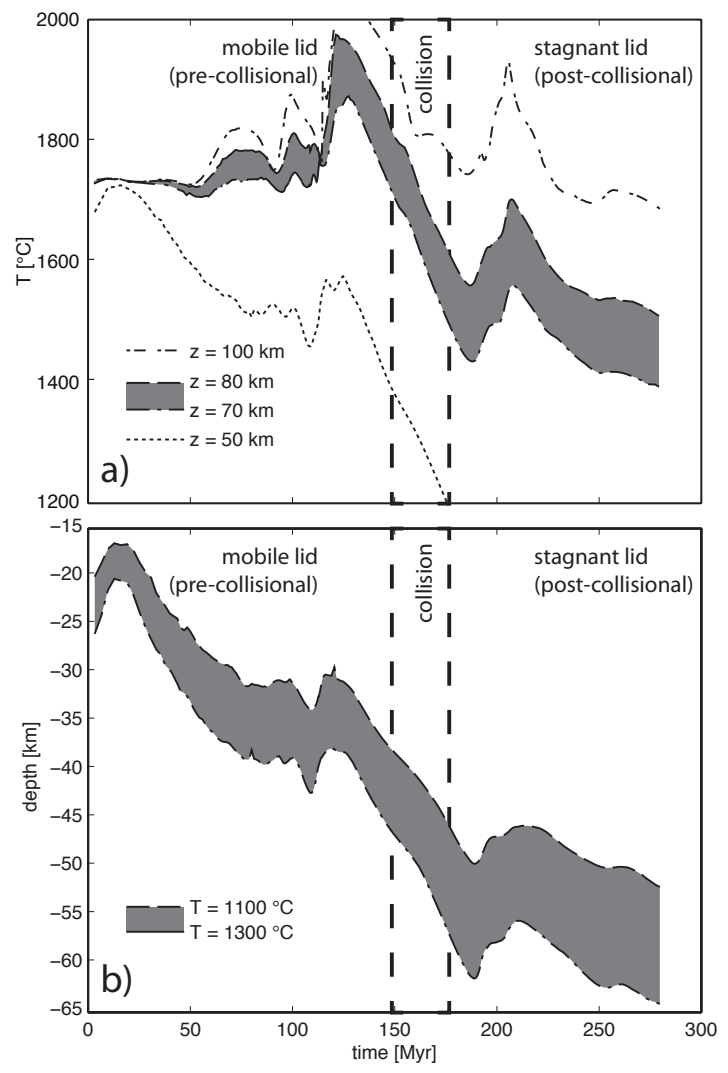

Figure 9: a) Temperature at $50 \mathrm{~km}$ (dotted), between 70 and $80 \mathrm{~km}$ depth (gray) and at $100 \mathrm{~km}$ (dot-dashed) as a function of time. b) Isothermal depth (between $1100^{\circ}$ and $1300^{\circ}$ ) underneath the ridge. 


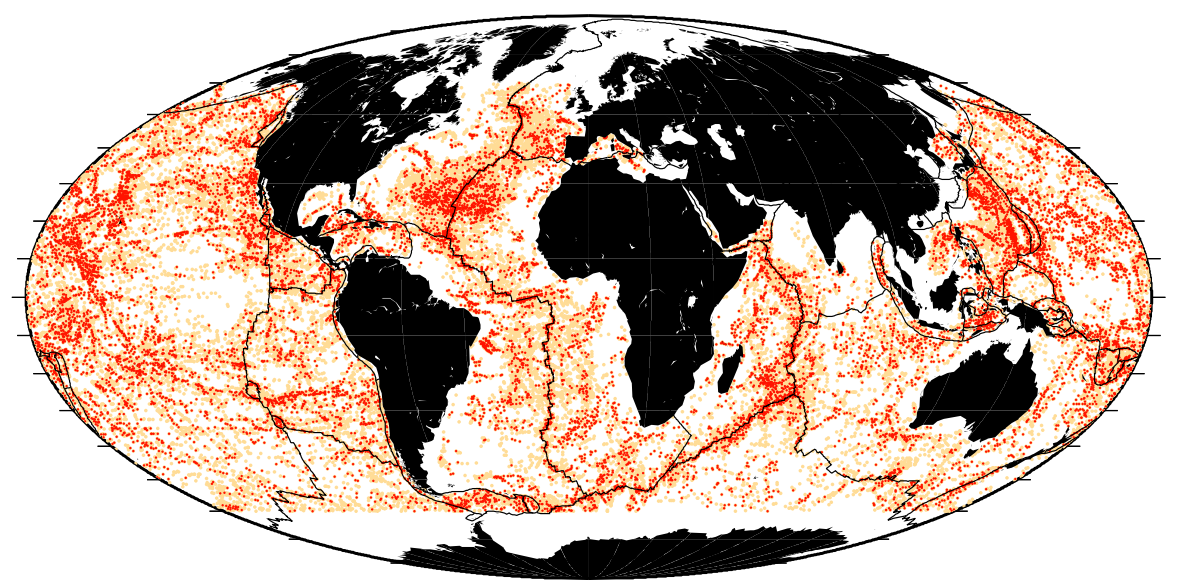

28

Supplementary figure: location of seamounts higher than $500 \mathrm{~m}$ (orange dots) and $1000 \mathrm{~m}$ (red dots). Fast spreading ridges (EPR, Pac-Ant, and SEIR) are seemingly deprived of seamounts with respect to slowspreading (for example North and Central Atlantic, CIR) and ultraslow spreading ridges (SWIR). 


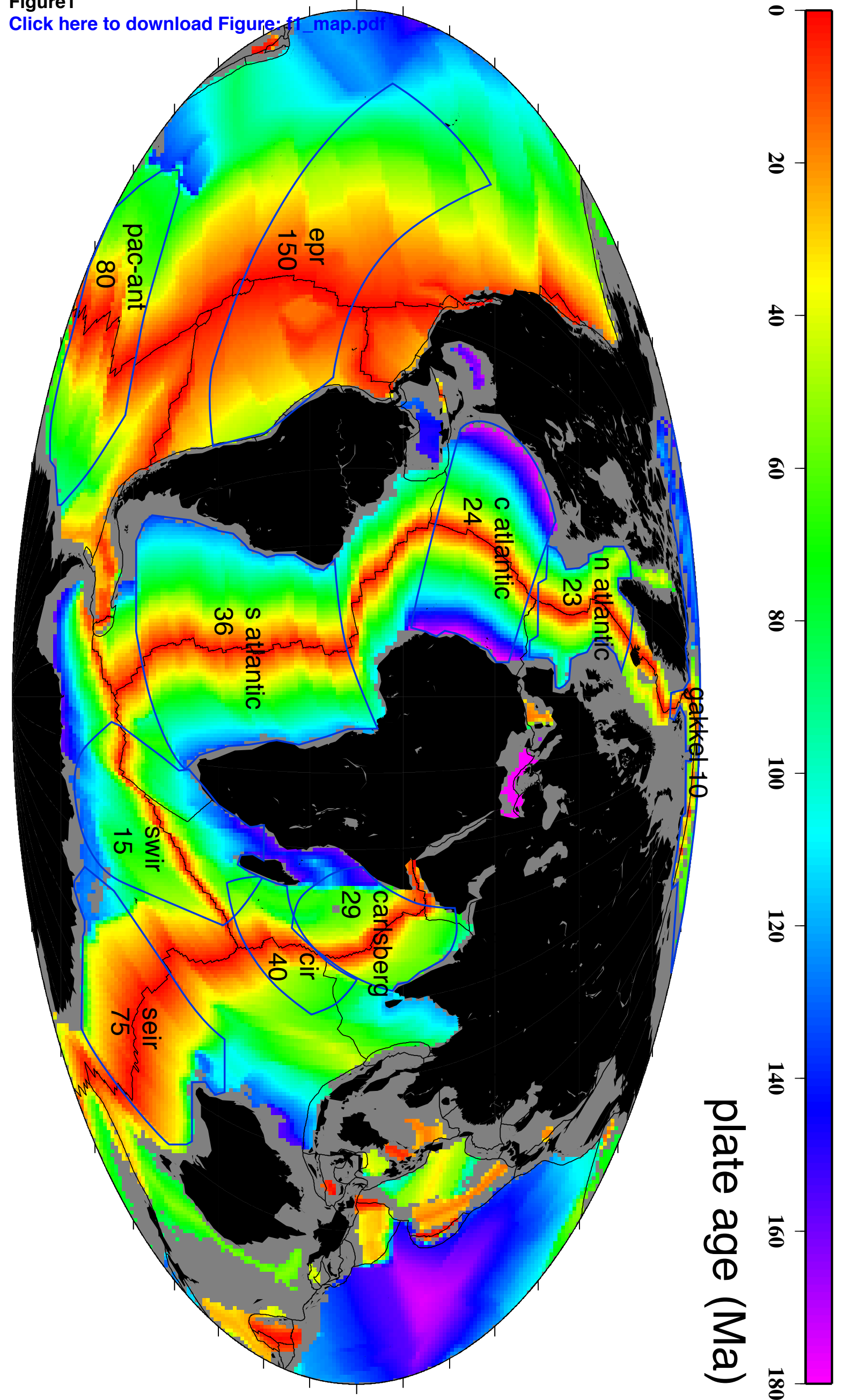


Click here to download Figure: f2_tomov40.pdf

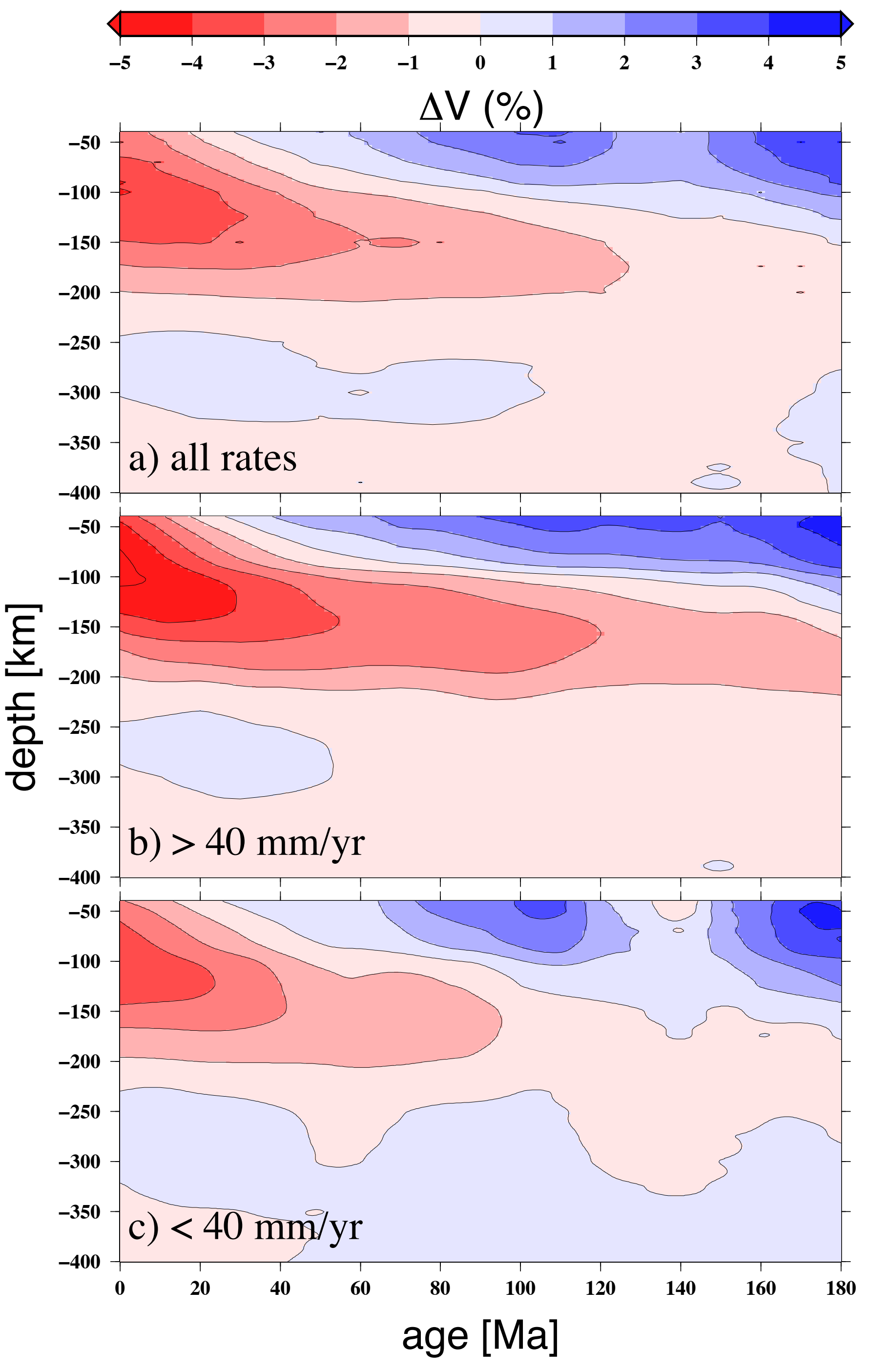


Click

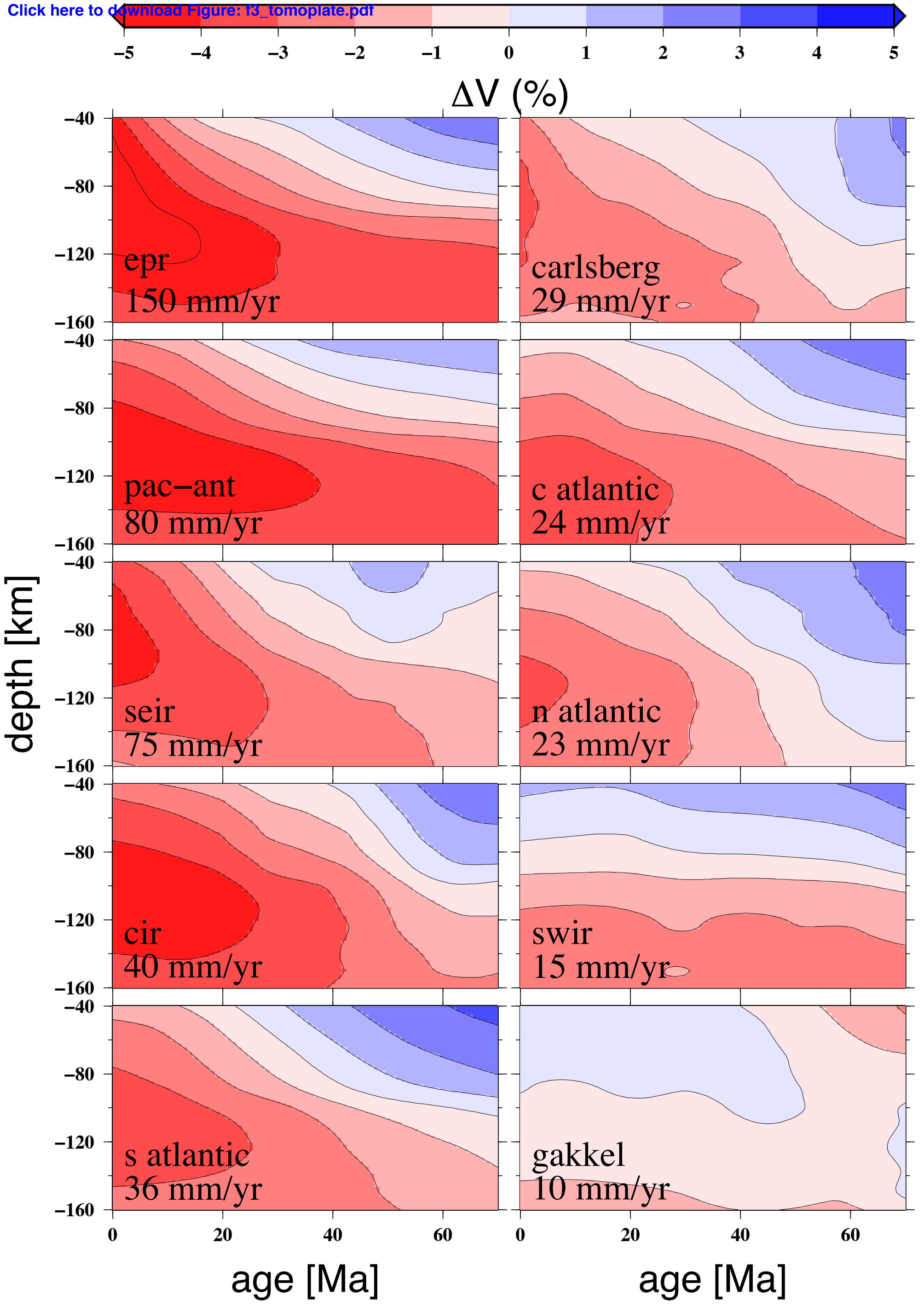



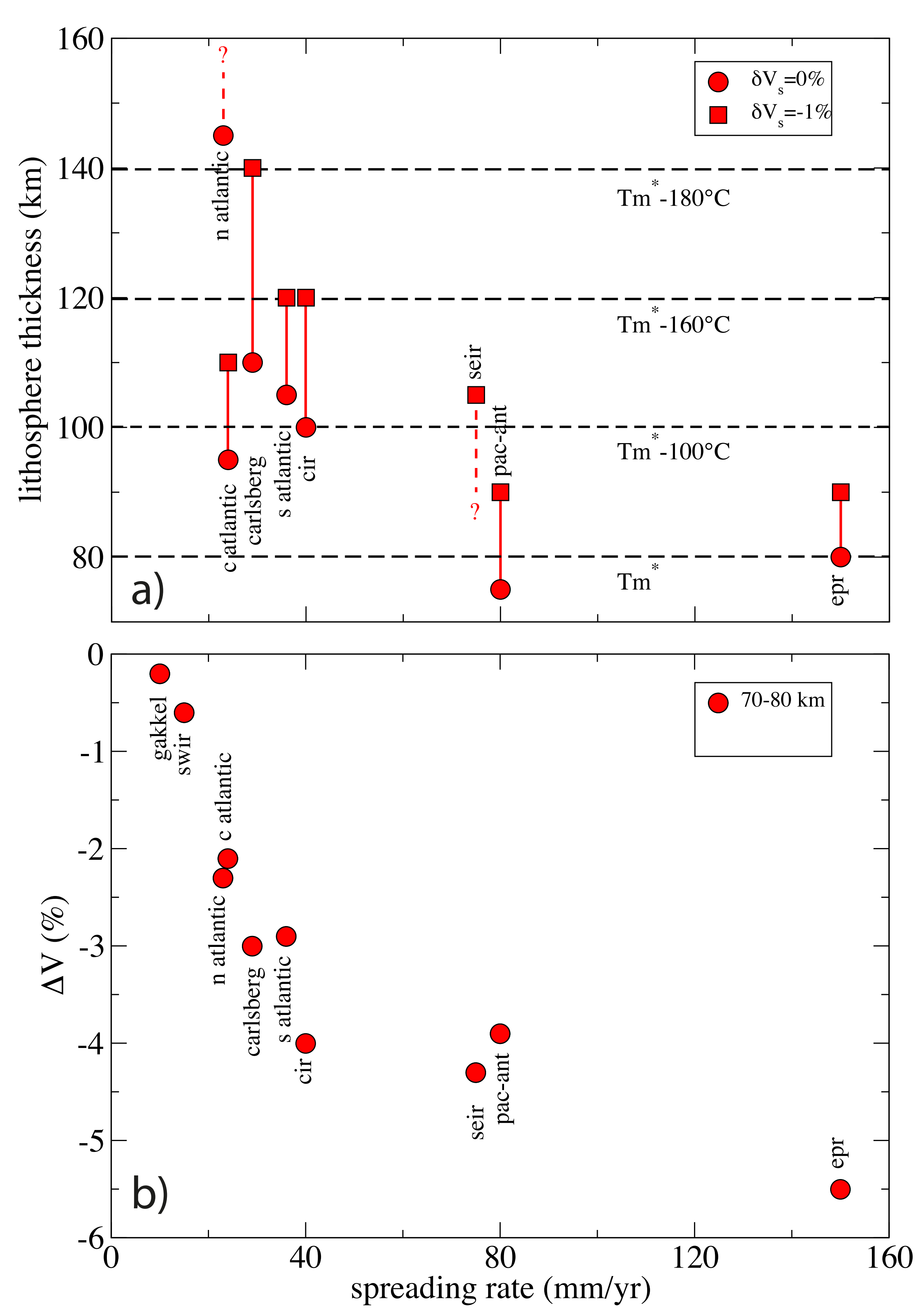
Click here to download Figure: f6_streamLR.pdf
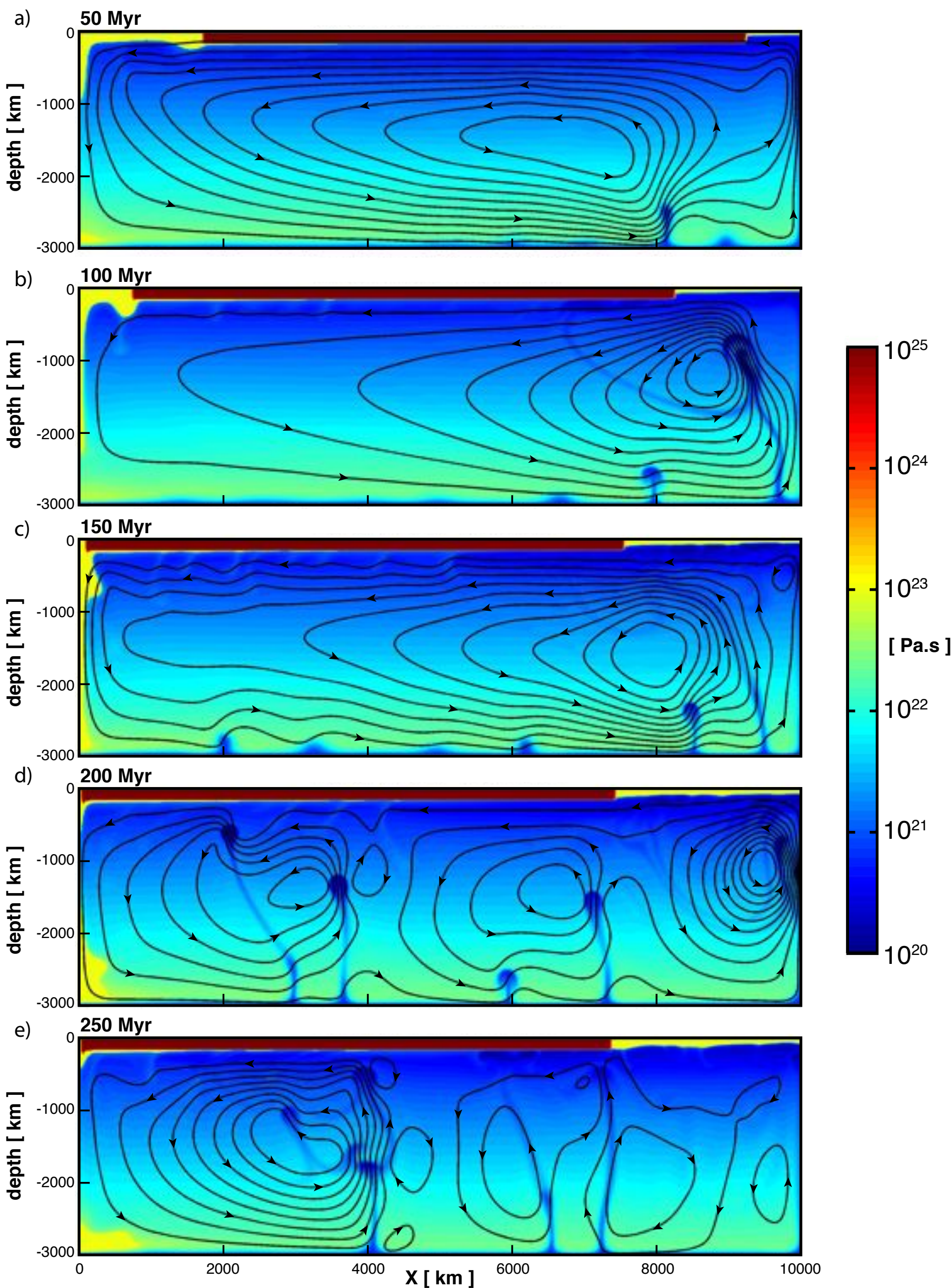


\section{Figure 76}

Click here

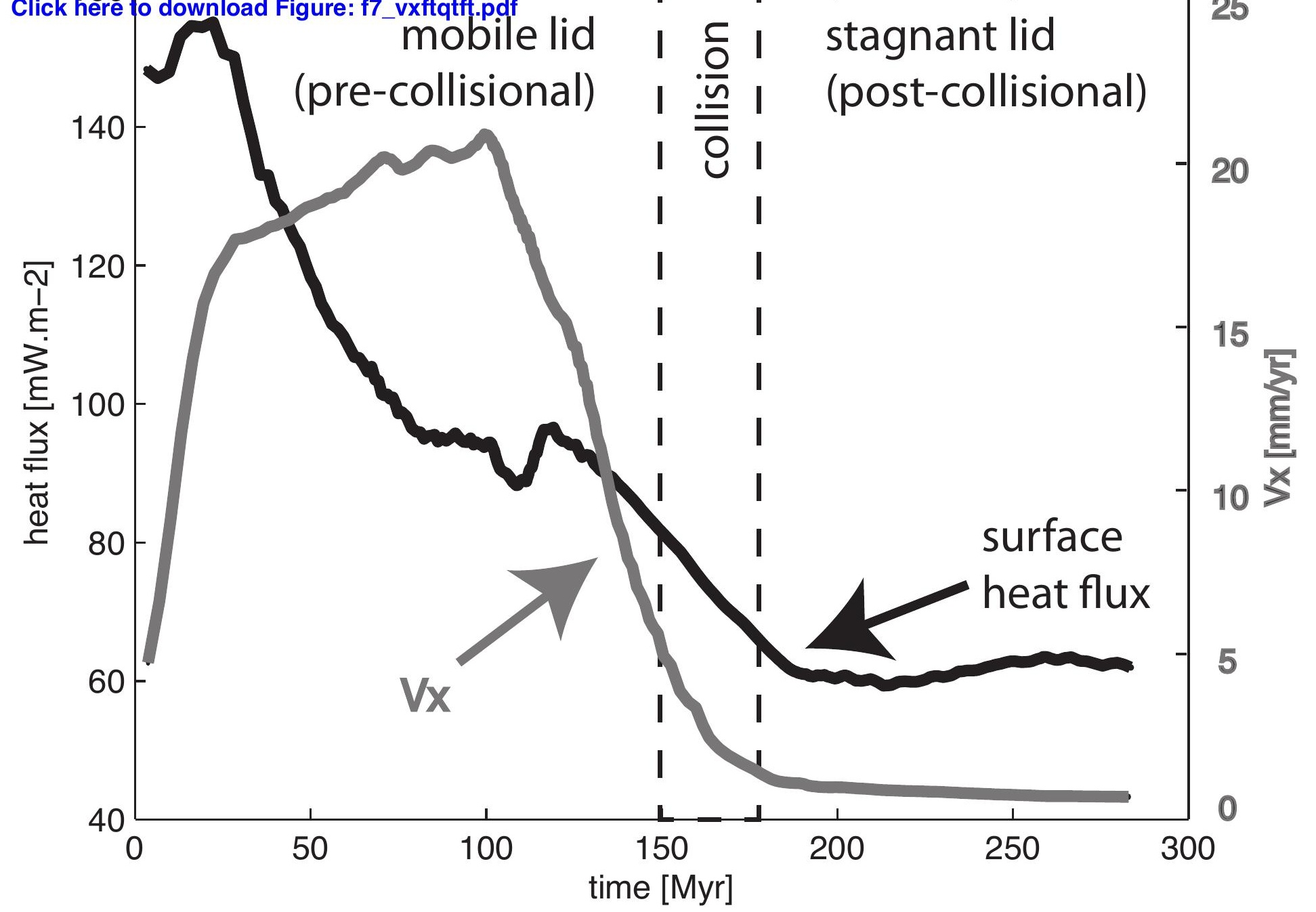

(pre-collisional) I $\stackrel{\frac{\sigma}{n}}{=}$ I (post-collisional) 


\section{Figure $8100 \mathrm{Myr}$}

Click

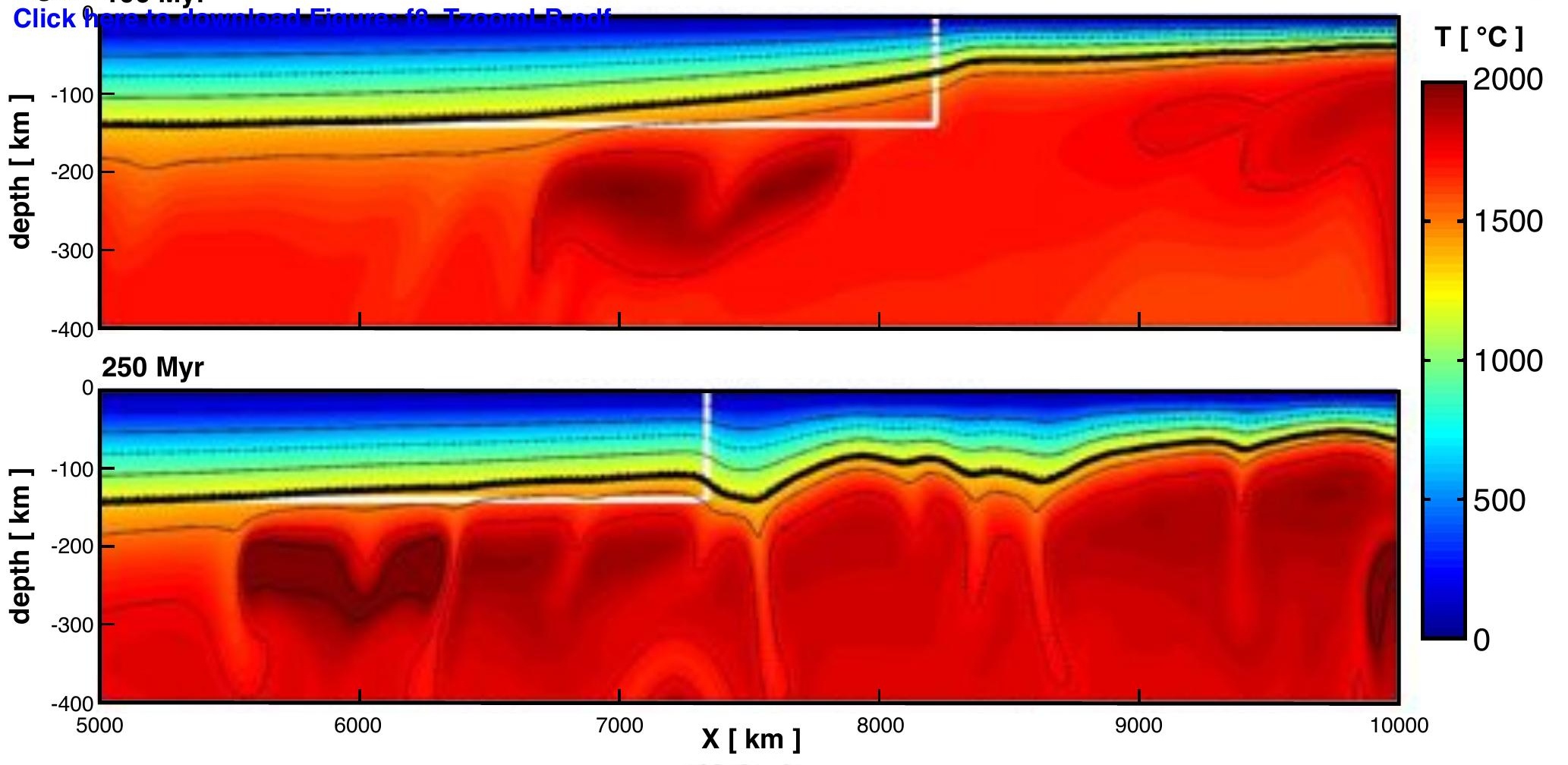




\section{Figese8}

Click here to download Figure: fig tipftzitt3.pgdf
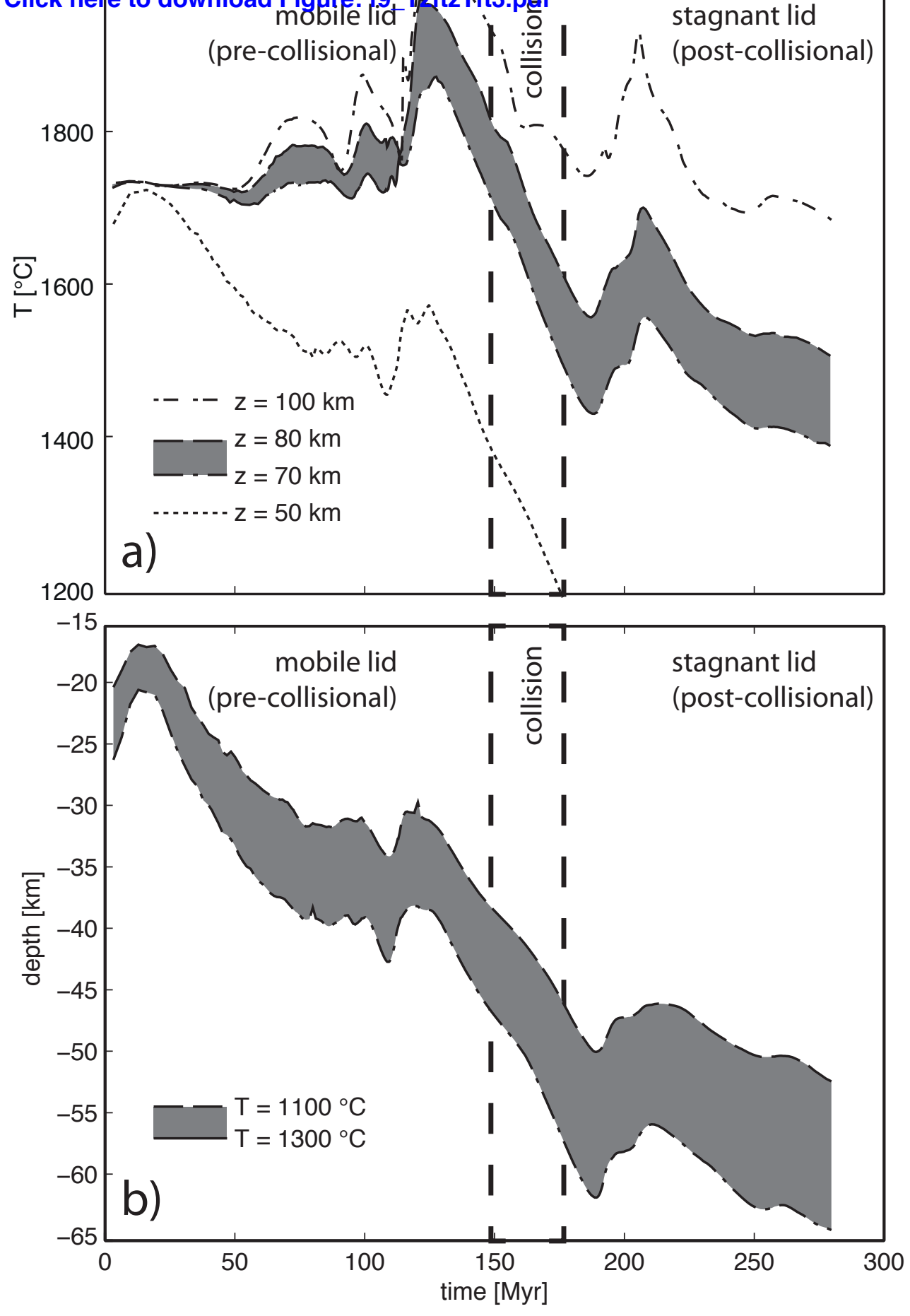